\title{
Comprehensive Characterization of Polymeric Composites Reinforced with Silica Microparticles Using Leftover Materials of Fused Filament Fabrication 3D Printing
}

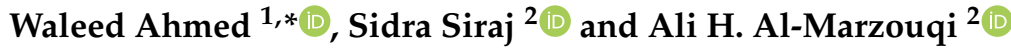 \\ 1 Engineering Requirements Unit, COE, United Arab Emirates University, Al Ain 15551, United Arab Emirates \\ 2 Chemical Engineering Department, COE, United Arab Emirates University, \\ Al Ain 15551, United Arab Emirates; sidra.siraj@uaeu.ac.ae (S.S.); hassana@uaeu.ac.ae (A.H.A.-M.) \\ * Correspondence: w.ahmed@uaeu.ac.ae
}

check for

updates

Citation: Ahmed, W.; Siraj, S.; Al-Marzouqi, A.H. Comprehensive Characterization of Polymeric Composites Reinforced with Silica Microparticles Using Leftover Materials of Fused Filament Fabrication 3D Printing. Polymers 2021, 13, 2423. https://doi.org/ $10.3390 /$ polym 13152423

Academic Editor:

Mohammad Arjmand

Received: 9 June 2021

Accepted: 17 July 2021

Published: 23 July 2021

Publisher's Note: MDPI stays neutral with regard to jurisdictional claims in published maps and institutional affiliations.

Copyright: (c) 2021 by the authors. Licensee MDPI, Basel, Switzerland. This article is an open access article distributed under the terms and conditions of the Creative Commons Attribution (CC BY) license (https:// creativecommons.org/licenses/by/ $4.0 /)$.
Abstract: Silica exhibits properties such that its addition into polymeric materials can result in an enhanced overall quality and improved characteristics and as a result silica has been widely used as a filler material for improving the rheological properties of polymeric materials. The usage of polymers in three-dimensional printing technology has grown exponentially, which has increased the amount of waste produced during this process. Several polymers, such as polypropylene (PP), polyvinyl alcohol (PVA), polylactic acid (PLA), and nylon, are applied in this emerging technology. In this study, the effect of the addition of silica as a filler on the mechanical, thermal, and bulk density properties of the composites prepared from the aforementioned polymeric waste was studied. In addition, the morphology of the composite materials was characterized via scanning electron microscopy. The composite samples were prepared with various silica concentrations using a twin extruder followed by hot compression. Generally, the addition of silica increased the tensile strength of the polymers. For instance, the tensile strength of PVA with $5 \mathrm{wt} \%$ filler increased by $76 \mathrm{MPa}$, whereas those of PP and PLA with $10 \mathrm{wt} \%$ filler increased by 7.15 and $121.03 \mathrm{MPa}$, respectively. The crystallinity of the prepared composite samples ranged from $14 \%$ to $35 \%$, which is expected in a composite system. Morphological analysis revealed the random dispersion of silica particles and agglomerate formation at high silica concentrations. The bulk density of the samples decreased with increased amount of filler addition. The addition of silica influenced the changes in the characteristics of the polymeric materials. Furthermore, the properties presented in this study can be used to further study the engineering design, transportation, and production processes, promoting the recycling and reuse of such waste in the same technology with the desired properties.

Keywords: polymers; silica; nylon; waste; 3D printing

\section{Introduction}

The global plastic consumption has drastically increased during the previous century, considerably increasing the amount of generated plastic waste [1]. Researchers worldwide have been attempting to develop sustainable solutions to address the increase in plastic waste and preserve the environment [2]. Among the commonly used polymeric materials, high-density polyethylene (HDPE), polypropylene (PP), and nylon are widely used in industries ranging from domestic packaging to automotive applications, primarily to enhance the mechanical properties of materials [3-7]. In addition, among bio-based polymers, polylactic acid (PLA) and polyvinyl alcohol (PVA) are widely preferred in applications involving hydrogels, catalysts, and strengthened materials. They are even used in rapid manufacturing and prototyping to develop products such as packaging applications [8-11]. Figure 1 shows the polymeric long-chain molecular structures of PLA, PP, PVA, and nylon. 
(a)

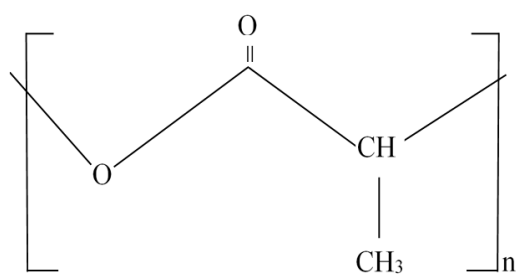

(c)

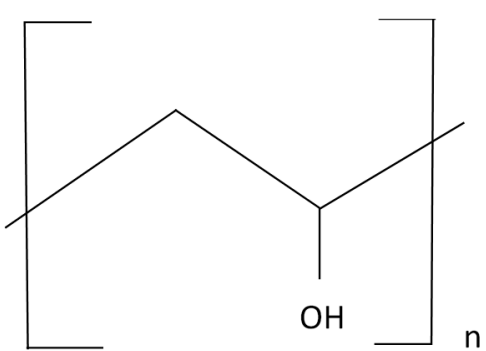

(b)

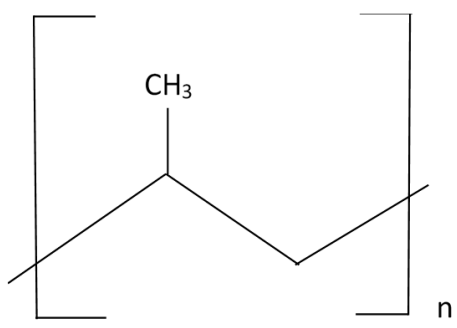

(d)

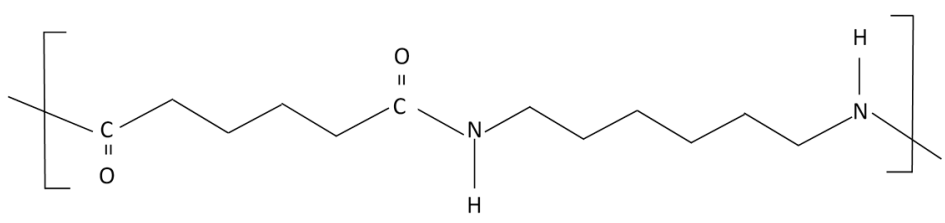

Figure 1. Polymer structures of (a) PLA, (b) PP, (c) PVA, and (d) nylon 6,6.

The recycling of polymeric waste materials is being increasingly studied to achieve a sustainable approach [12-14]. Innovative techniques have also been developed to convert thermoset plastics into thermoplastic ones to improve their recycling $[15,16]$. Compared with other waste disposal techniques, recycling is considered a more economical and practical approach. However, mechanical recycling is limited because of the toxic compounds associated with recycling, even though it is a highly resource-effective approach. The three-dimensional (3D) printing technology has emerged as the latest sustainable technique to promote the use plastic waste as feedstock material $[1,17,18]$.

Commercial PLA degrades at a slower rate under natural environmental conditions, resulting in its prolonged existence [19]. In addition, PLA disposal results in the loss of several substantial hydroxyl components that can be effectively used as monomers. Therefore, PLA should be recycled to extract and reutilize such valuable compounds that can be used to develop various monomers [20]. Moreover, PLA can be easily separated from other polymers because of its higher density [9].

Polypropylene (PP), which is extensively used as an industrial-scale commodity polymer, is another polymer that has drawn considerable attention because of its numerous advantages, including its lightweight nature, high moisture resistance, chemical stability, and ease of processing [21]. PP has a high melting temperature and exhibits superior mechanical and electrical characteristics compared with other polymers [22,23]. It is also considered an environmentally friendly insulation material and power capacitor. However, its direct manufacturing usage is limited because of its low-temperature impact strength [24].

PVA is well known as the largest synthetically produced polymer worldwide [25]. PVA is the chosen polymer for many biochemical, pharmaceutical, and biological applications because of its high chemical resistance, outstanding water solubility and biodegradability [26]. The ability of PVA to be produced as a hydrogel makes it adaptable to complex medical applications such as synthetic organ (ex; heart) production [8]. Even though PVA exhibits good stability, it provides no essential benefits as a polymer itself. However, because it functions as a good host, it can be used as an excellent carrier to deposit valuable compounds to the required sites for realizing enhanced properties. Hence, it is widely preferred to be used in polymer composite materials as a matrix [27].

The polymers in synthetic fibres, such as nylon, have also been used to develop rubbers and resins [28]. In addition, fibre-rubber composite mixes have drawn considerable attention because they exhibit better properties than pure fibre-based materials. For example, the addition of fillers to fibres can result in improved mechanical strength and surface wettability. Therefore, recent studies have focused on fibre composites [29]. 
As mentioned earlier, the utilization of pure polymeric materials is not preferred because of their inferior properties compared with those of polymer composite materials containing a weighted percentage of filler or particulate matter [30-32]. A study with talc filler addition promoted this idea as well for thin sheet applications [33]. The addition of fillers results in enhanced mechanical and thermal properties and improves polymers' conductivity and barrier properties. Therefore, polymer composite materials are preferred over pure polymers in most industrial applications such as packaging material [34-37]. Inorganic fillers, such as calcium carbonate $\left(\mathrm{CaCO}_{3}\right)$, titania $\left(\mathrm{TiO}_{2}\right)$, silica $\left(\mathrm{SiO}_{2}\right)$, and graphene, have been used as fillers [38-41]. Among the commonly used fillers, silica is considered an excellent choice for various applications because of its highly unreactive nature, high chemical and thermal stability, and the large number of silanol groups that can be easily functionalized [42]. Silica has thus been widely used as a filler in reinforced building materials and improves the thermal and mechanical properties of composites [7,43-45]. Because silica exhibits excellent properties, using silica as a filler has emerged as an interesting research field.

In general, fused filament fabrication (FFF), also known as fused deposition modelling (FDM) or more commonly well-known as 3D printing, is one of the most traditional, affordable and easy to use 3D printing technologies. Although there are many alternative meanings for 3D printing technology, according to ISO/ASTM 52900:2015-Additive manufacturing-General principles-Terminology, 3D printing is defined as: "[the] fabrication of objects through the deposition of a material using a print head, nozzle, or another printer technology" while additive manufacturing (AM) is "[the] process of joining materials to make parts from 3D model data, usually layer upon layer". 3D printing offers low cost, low energy consumption, and simple modelling techniques specifically for small intricate parts, making it an attractive fabrication technique $[1,18]$. Although the advances in 3D printing have led to growth in rapid testing and prototyping, which has resulted in the spread of knowledge across fields, the exponential rise of 3D printing has also resulted in increased waste production [36-38]. Fortunately, 3D printing can also be performed using waste raw materials, effectively conserving energy. A more centralized recycling approach could benefit from the usage of 3D printing technology because household waste constitutes approximately $31 \%$ of the residual waste $[1,46]$. Moreover, the waste of 3D printed composite material can also be easily recycled, making this method an eco-friendly disposal method as well for a wide range of composites [37].

Continuously produced reinforced fibres have already been studied [47]. The incorporation of silica particles into polymers, such as PLA, PP, PVA, and nylon, for 3D printing, enhances the material characteristics [48,49]. For instance, PLA-/silica-based medical-grade scaffolds have been developed using the 3D printing technology $[35,50]$. PVA-/silica-based fibres have also been incorporated with 3D printing to develop drug delivery patches [51]. Moreover, it has been demonstrated that the addition of nano-silica in PP resulted in the improvement of foam quality-as assessed from the well-defined and regular cell structures with absence of cell coalescence-as well as an increase in expansion ratio and decrease in foam density [52], and that significant improvements in the thermal stability were noticed with an increase in the percentage of nanosilica particles whereas the mechanical properties were improved [53], especially polypropylene modified by blending elastomer and nano-silica as the dispersed polyolefin elastomer could transfer and homogenize external mechanical forces [54], but for the electrical properties, when nano- $\mathrm{SiO}_{2}$ was more dispersed in the PP phase, the space charge improvement effect was best [55].

Functionally graded materials (FGMs), such as the functionally graded nylon, involve the selected transitions concerning the material properties for enhancing the functional value of the corresponding component. Although FGMs are widely used in several engineering applications, the development of complicated parts from FGMs has been limited. However, the effective usage of nylon in 3D applications has been promoted in emerging research [56,57], enabling the potential for reutilizing the produced wastes using $3 \mathrm{D}$ tech- 
niques. Inevitably, reusing polymeric waste as a feedstock material is an added advantage associated with 3D printing applications [11,58]. Fused filament fabrication (FFF) is considered a simple and nonexpesive additive manufacturing technology that has unlimited applications [59-61], especially when using recycled plastics that could be further enhanced with different fillers. Silica particles are considered superior alternative fillers for improving the properties of polymers [62]. The literature also supports using in situ-synthesized silica particles to develop composite materials with improved properties [63,64].

In this study, polymeric waste obtained from the 3D printing of four different polymers (PP, PVA, PLA, and nylon) was collected to study the effect of the addition of silica on the mechanical and thermal properties of the developed materials. This study can help us understand the difference between the properties of commonly used polymers when considering identical particle reinforcements. In addition, this study promotes the idea of reusing composite materials in a similar $3 \mathrm{D}$ printing application.

\section{Materials and Methods}

Assorted leftover polymers (PLA, PP, PVA, and nylon) from the 3D prototyping laboratories of the United Arab Emirates University (UAEU) were collected, sorted, and shredded using a DIY shredder machine [65]. Notably, the shredded material contained no residue [66] because the plastic waste of the university laboratory was carefully sorted. Silica, which was collected from the local environment, was cleaned, sieved, and ground using a heavy-duty grinder (planetary ball mill, PL-400, Retsch, Germany). The detailed grinding process and composition of the sand sample are described elsewhere [67].

The polymeric waste samples were cut and further shredded using a mechanical shredder. The shredded particles were approximately $1 \mathrm{~mm}$ in length, which was sufficiently small for them to fit through the feed hopper of the extruder. In this study, various mixing ratios $(5,10$, and $15 \mathrm{wt} \%)$ of the final powdered form of silica $(<5 \mu \mathrm{m})$ were mixed with each set of polymeric waste. The polymer and microparticles were melt-blended into a composite material in a twin-screw extruder (MiniLab Rheomex CTW5, HAAKE, Karlsruhe, Germany). The melt blending procedure followed a closed-loop cycle set for approximately $5 \mathrm{~min}$ at $190^{\circ} \mathrm{C}$ with a rotational speed of $140 \mathrm{rpm}$. The same procedure was performed for each set of polymers alone (i.e., $0 \mathrm{wt} \%$ silica). After the closed-loop cycle, the blended material was extruded through a valve at the exit of the extruder to collect the composite material for the compression molding step. In this stage, approximately $1 \mathrm{~g}$ of the extruded sample was chopped and thermally compressed using a Carver's press (Carver ${ }^{\mathrm{TM}}$ Lab Presses, IN 46992-0554 USA) under 5000 psi and at the same extrusion temperature and time set (i.e., $190{ }^{\circ} \mathrm{C}$ and $5 \mathrm{~min}$ ). This process was performed for the extruded samples obtained from each polymer with the desired filling ratio. The samples obtained from this process were thin sheets of the composite material investigated for their mechanical and thermal characteristics. Figure 2 shows the material preparation, extrusion, and compression processes.

\subsection{Mechanical Characterization}

Different mechanical properties of the materials were tested using a universal testing machine (UTM, Shimadzu, Kyoto, Japan) to study the effect of silica reinforcement on the polymer/composite samples. The thin composite sheets obtained from the compression molding stage were used to prepare the tensile test samples following the American Standard Society for Testing and Materials (ASTM)-D 638 norms. The specific dimensions were achieved using a specialized manual blanking machine (Exacta Model-JFP, Bengaluru, India). 


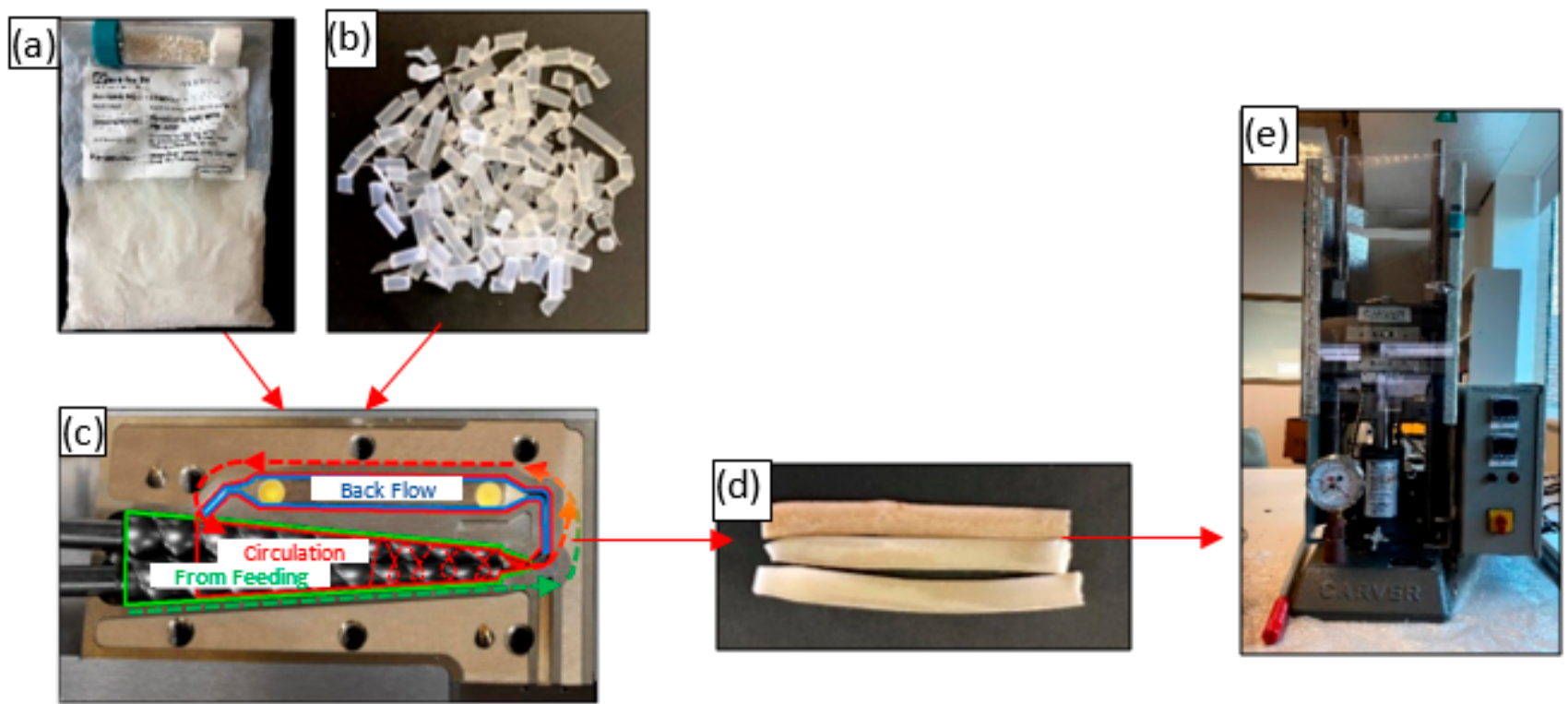

Figure 2. Material preparation: (a) powdered silica, (b) polymer sample, (c) twin-screw extruder (top view), (d) extruded filament, and (e) compression molding machine.

A common problem observed during the cutting process is that the clearance between the die and the punch must be a function of the thickness of the sample because the clearance represents the ratio to the thickness of the sample [68,69]. Consequently, the sheared edges might be affected, resulting in forming of rough surfaces, which affect the sample's mechanical properties and could contribute to inconsistent failure. Generally, the stress concentrations at the ends of the sample can affect the mechanical behaviour of the sheets. The pressure created on the punch and die during the blanking process can lead to stress distributions, which can influence the difference in geometry at a given burr size and the surface of the intersection [70].

Dumbbell-shaped tensile test specimens were prepared using the blanking machine. The dimensions (i.e., the length (l), width (w), and thickness ( $t)$ ) of each set of the composite samples are presented in Table 1 . The varying thicknesses of the pieces can be directly attributed to the processing of the polymers themselves. The corresponding mechanical properties were investigated using a $10 \mathrm{kN}$ load cell with a $5-\mathrm{mm} / \mathrm{min}$ crosshead motion. Five replicates measurements were performed for obtaining increased accuracy, which is represented as standard deviations (SDs) in the plots of the results. Figure 3 shows the dimensions of one of the tensile test specimens, and Figure 4 shows the blanking process and the tensile testing machine.

Table 1. Dimensions of the prepared tensile test specimens.

\begin{tabular}{ccccc}
\hline \multirow{2}{*}{ Polymer Type } & \multicolumn{4}{c}{ Dimensions $\mathbf{( 1 \times \mathbf { w } \times \mathbf { t } ) \mathbf { ( m m } )}$} \\
\cline { 2 - 5 } & $\mathbf{0} \mathbf{w t} \%$ & $\mathbf{5} \mathbf{w t} \%$ & $\mathbf{1 0} \mathbf{w t} \%$ & $\mathbf{1 5} \mathbf{w t} \%$ \\
\hline PLA & $10 \times 4 \times 0.06$ & $10 \times 4 \times 0.06$ & $10 \times 4 \times 0.06$ & $10 \times 4 \times 0.08$ \\
\hline PP & $10 \times 4 \times 0.1$ & $10 \times 4 \times 0.1$ & $10 \times 4 \times 0.12$ & $10 \times 4 \times 0.12$ \\
\hline PVA & $10 \times 4 \times 0.06$ & $10 \times 4 \times 0.08$ & $10 \times 4 \times 0.12$ & $10 \times 4 \times 0.12$ \\
\hline Nylon & $10 \times 4 \times 0.04$ & $10 \times 4 \times 0.06$ & $10 \times 4 \times 0.1$ & $10 \times 4 \times 0.1$ \\
\hline
\end{tabular}




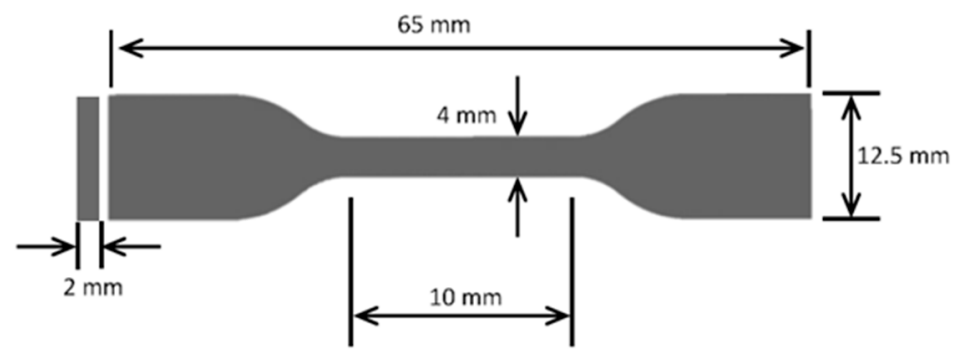

Figure 3. Dimensions of one of the prepared samples.
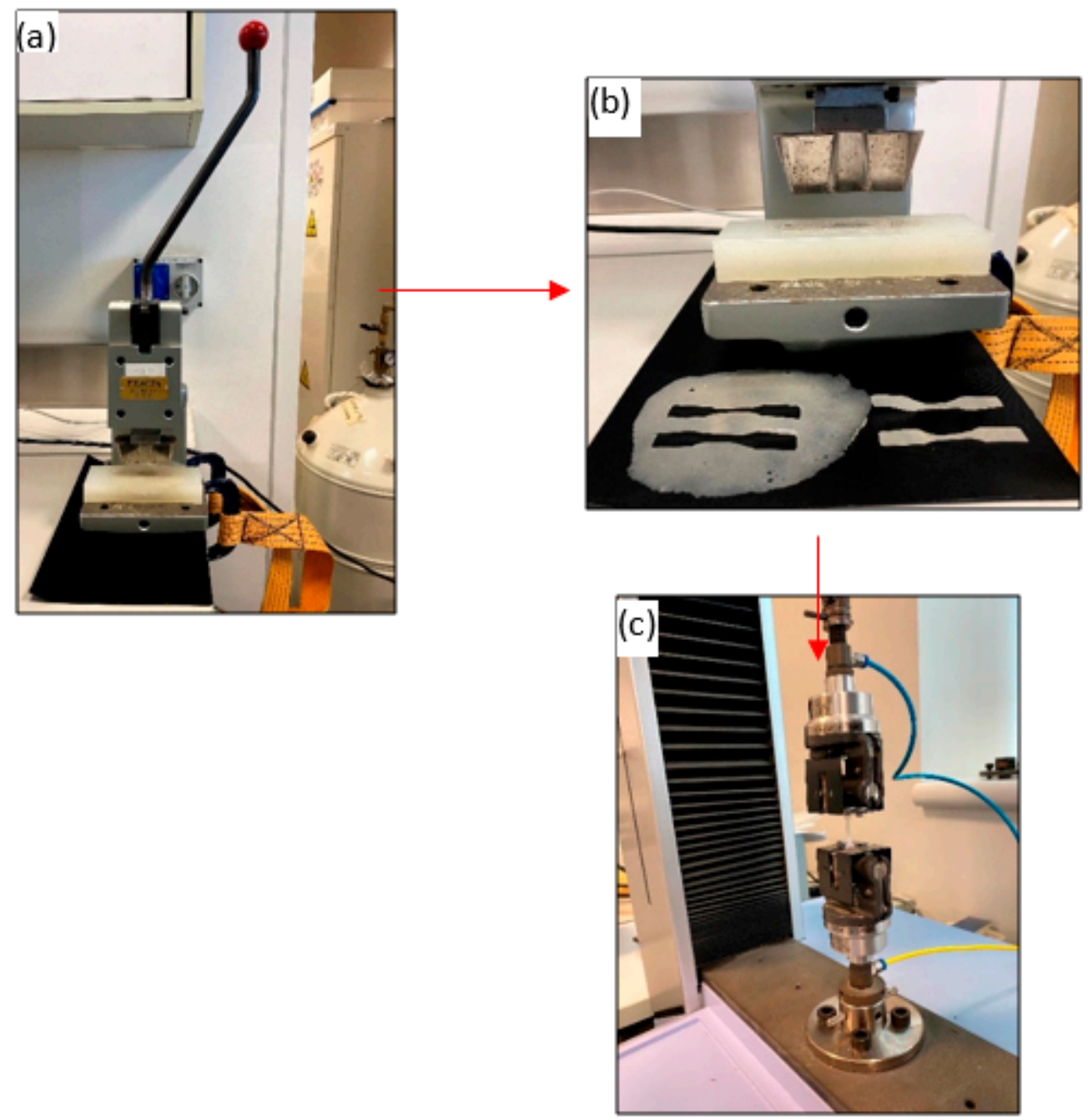

Figure 4. (a) Blanking machine; (b) Dumbbell shape samples after blanking process (c) Tensile testing machine with a sample.

\subsection{Differential Scanning Calorimetry (DSC)}

The melting temperatures $(\mathrm{Tm})$ and crystallization temperatures $(\mathrm{Tc})$ of the control samples, i.e., the pure polymeric sheets and the prepared composite sheets, were determined using modulated differential scanning calorimetry (Discovery DSC 25, TA Instruments, New Castle, DE, USA). Samples of approximately 5-10 mg were heated from 20 to $200^{\circ} \mathrm{C}$ at a heating rate of $40{ }^{\circ} \mathrm{C} / \mathrm{min}$ to remove the thermal history of the polymer composite material. After the thermal history was eliminated, all the samples were cooled from $200{ }^{\circ} \mathrm{C}$ to room temperature $\left(20^{\circ} \mathrm{C}\right)$ at $10^{\circ} \mathrm{C} / \mathrm{min}$ for recording Tc and subsequently heated from 
$20{ }^{\circ} \mathrm{C}$ to $200{ }^{\circ} \mathrm{C}$ at $10{ }^{\circ} \mathrm{C} / \mathrm{min}$ to record $\mathrm{Tm}$. All the experiments were carried out under an inert flowing $\mathrm{N}_{2}$ atmosphere.

\subsection{Scanning Electron Microscopy (SEM)}

A scanning electron microscope (JSM 6390A, JEOL, Peabody, MA, USA) operated at $2 \mathrm{kV}$ with a spot size of 40 was used to image the prepared composite sheet materials. The composite sheets were placed on an Al pin mount adapter using double-sided carbon tape. They were then sputter-coated with $\mathrm{Au}(\mathrm{Au} / \mathrm{C})$ using a sputter coater under vacuum to avoid electrostatic charging during the examination. This was also done to improve the conductivity of the sample and enhance the quality of the images. The scanning electron microscope was operated in high-vacuum mode with an acceleration voltage of $15 \mathrm{kV}$, and images were acquired. The working distance for the SEM was $1.5 \mathrm{~mm}$

\section{Results and Discussion}

\subsection{Mechanical Characterization}

The developed composite sheet material was used to prepare dumbbell-shaped specimens for mechanical testing. Several samples were prepared from each specimen so that the tests could be repeated, improving the test's overall accuracy. A thickness gauge (model 547-526S, Mitutoyo, Kawasaki, Japan) with a resolution of $0.001 \mathrm{~mm}$ was used to determine the thickness of the samples at various locations along the gage length. The samples exhibiting consistent values were selected for further testing [71].

Figure 5 shows the the stress-strain curves of nylon mixtures, whereas in Figure 6 the stress-strain curves of the PLA blends are illustrated.

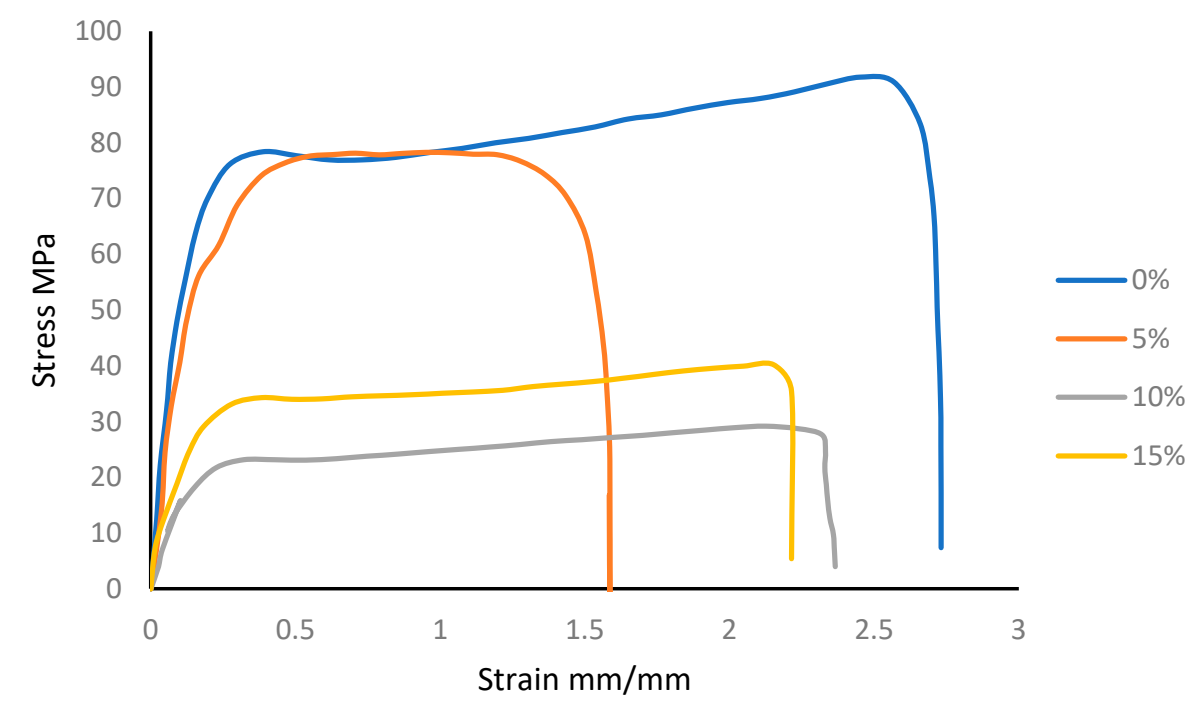

Figure 5. Nylon/silica stress-strain behavior.

Figure 7 shows that the TS of the samples increases with the addition of silica particles. In case of PP, the addition of silica results in a gradual decrease of the TS from $11.01 \mathrm{MPa}$ at $0 \mathrm{wt} \%$, which is similar to the value of $5.63 \mathrm{MPa}$ obtained at $15 \mathrm{wt} \%$ mentioned in the literature [72]. However, the TS value slightly increases from $6.96 \mathrm{MPa}$ at $5 \mathrm{wt} \%$ to $7.15 \mathrm{MPa}$ at $10 \mathrm{wt} \%$. This behaviour of PP has been previously reported to occur at a silica content of approximately $3 \mathrm{wt} \%$. This behaviour is likely to be associated with the stiff layers of silicate, which have a high aspect ratio, causing a high degree of interaction and suitable interfacial adhesion property. In addition, this behaviour contributes to the restriction of the free mobility of the polymer chains, increasing the TS value $[72,73]$. 


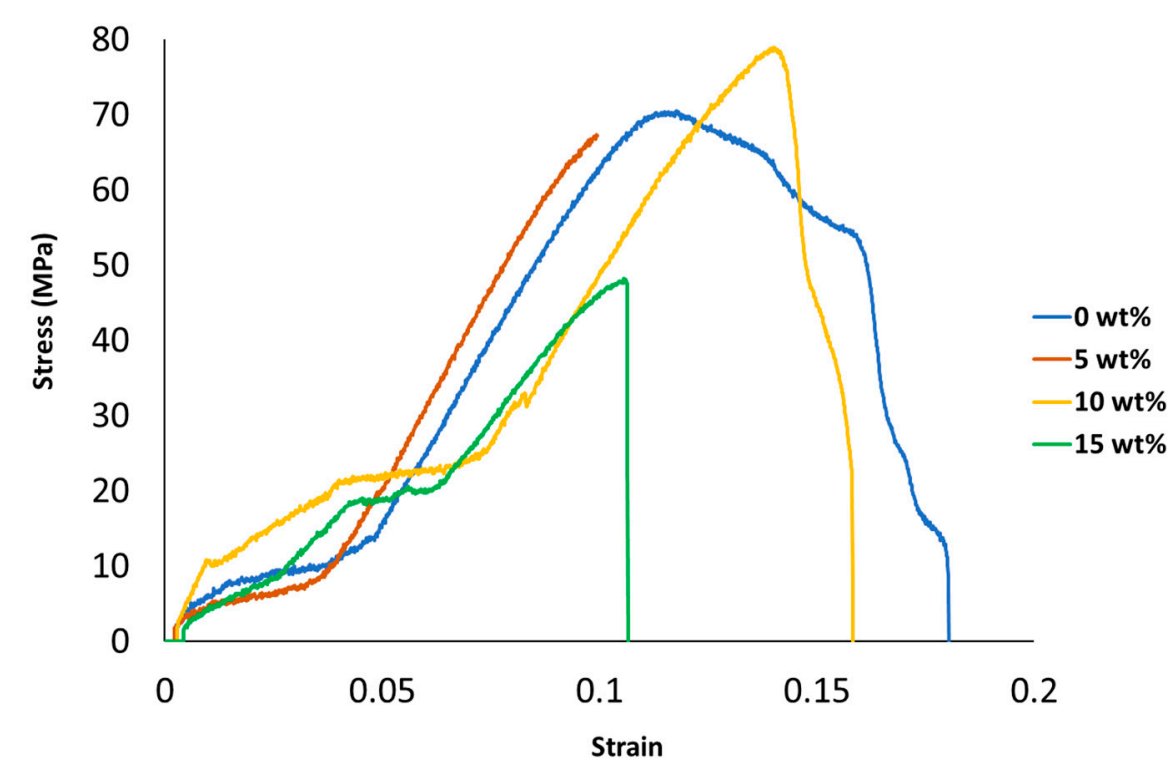

Figure 6. PLA/silica stress-strain behavior.

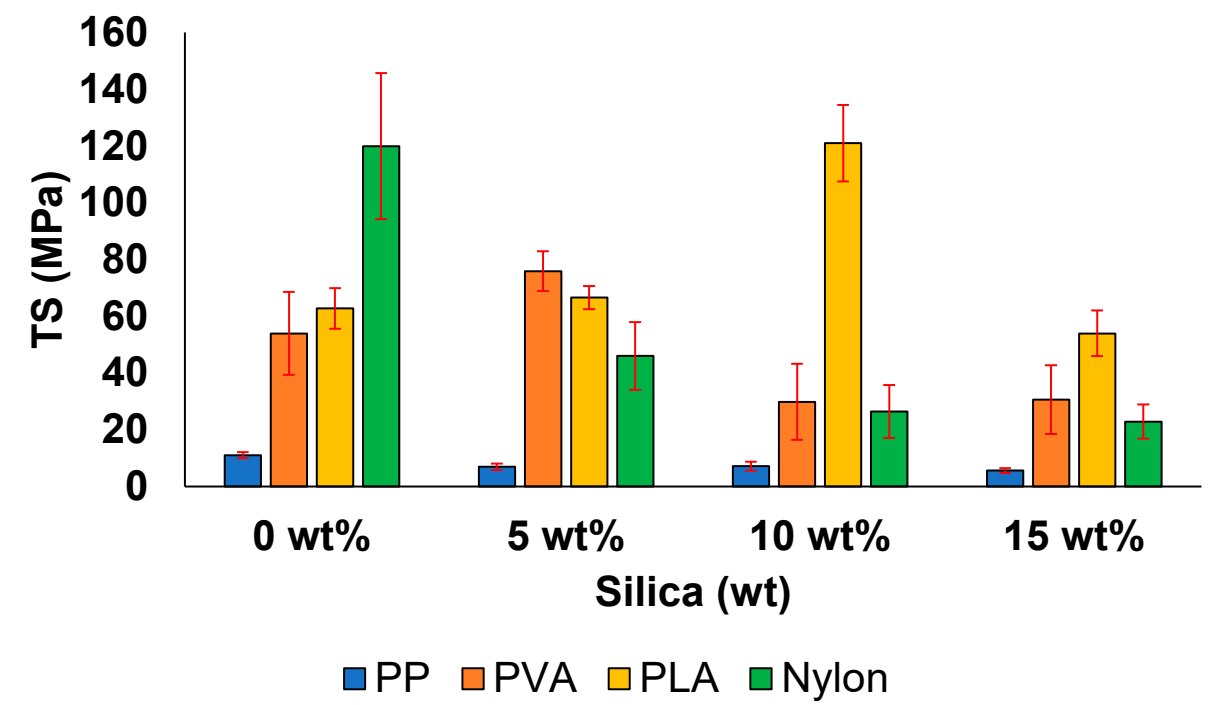

Figure 7. Tensile strength values of the prepared samples.

In the case of PVA, the TS value was observed to drastically increase from 54 to $76 \mathrm{MPa}$ with the addition of $5 \mathrm{wt} \%$ silica, indicating enhanced mechanical properties. The TS value decreased when considering higher silica contents. Similar mechanical values have been previously reported; for example, a TS value of $71.1 \mathrm{MPa}$ has been obtained for pure PVA [74]. The sharp rise in tensile strength can be related to the co-condensation observed at this composition, resulting in the increased uniformity and dispersion of the filler. However, the decrease in TS value at other filler compositions is associated with weak interactions between the matrix and filler [8].

In case of PLA, the TS value considerably decreased with the increasing silica concentration until the silica concentration reached $10 \mathrm{wt} \%$. This increase in the TS value directly corresponds to the positive effect of the addition of a filler into the matrix. At higher silica concentrations, the TS decreased to become $54 \mathrm{MPa}$, similar to the results of previous reports [67]. Similar values have been reported for PLA. However, beyond a specific weight concentration of filler, the mechanical properties tend to deteriorate because the lack of consistent mixing of particles contributes to stress concentration and results in failure [44]. 
In case of nylon, the TS value gradually decreased from $120 \mathrm{MPa}$ at $0 \mathrm{wt} \%$ to $23 \mathrm{MPa}$ at $15 \mathrm{wt} \%$. This is because the weak interfacial bonding caused by micro fillers results in the increased brittleness of the matrix, reducing the strength of the material [57].

The decrease in the TS value of all the samples can be attributed to the random dispersion of the filler inside the polymeric matrix. This can result in the direct agglomeration of particles beyond a filler content of $0 \mathrm{wt} \%$ or beyond the absolute weight concentration of the filler, which the polymer can withstand. This agglomeration results in defects and creates initiation spots that can lead to failure. Voids are commonly observed to form in polymer composite systems, adversely affecting their mechanical behaviour. In addition, the irregular shapes of the particles make them unable to uniformly transfer stress, resulting in diminished mechanical properties [72,73,75].

Figure 8 presents the toughness of the prepared composite materials. The toughness values of the PP and nylon samples are considerably greater than those of the PVA and PLA samples. The toughness, which is a measure for absorbing energy, decreased from $95 \mathrm{MPa}$ at $0 \mathrm{wt} \%$ silica to $6 \mathrm{MPa}$ at $15 \mathrm{wt} \%$ silica in case of PP. This decrease can be attributed to the agglomerates that affect the structural stability of the prepared composite materials, reducing the absorption of impact energy by the material and inducing crack formation at the interface of the material. To address this issue, several researchers have incorporated modifying agents that improve the impact resistance of materials [72,76].

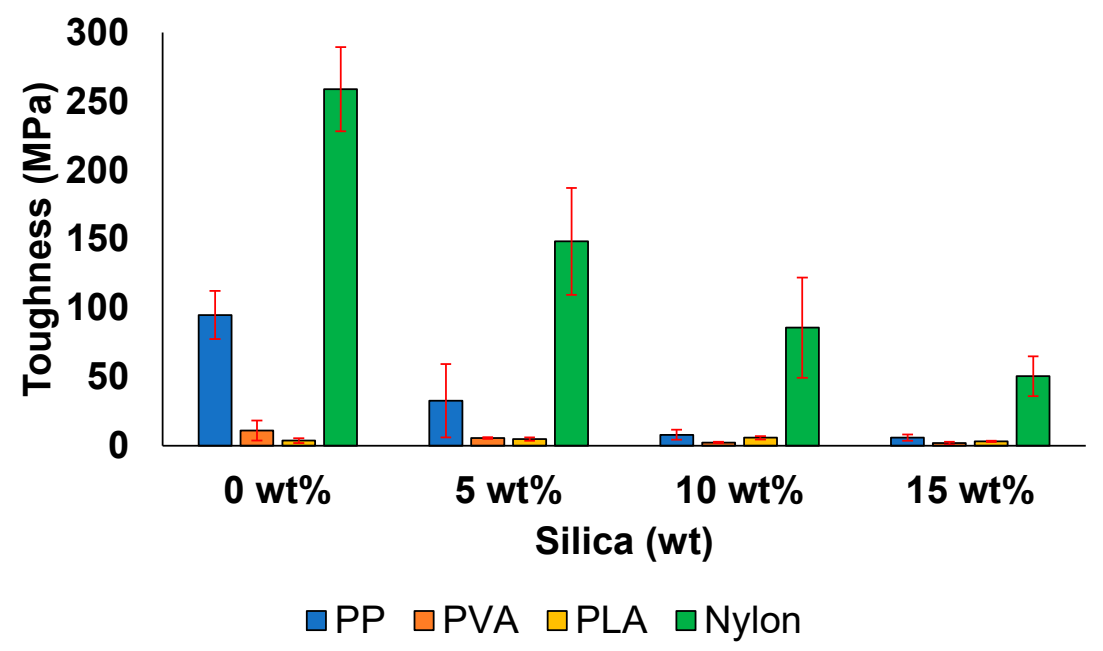

Figure 8. Toughness of the prepared composite materials.

The toughness value of PVA decreased by $82 \%$ (from 11 to $2 \mathrm{MPa}$ ) when silica content was increased from 0 to $15 \mathrm{wt} \%$. Such a substantial decrease in toughness has been observed in other PVA composite systems and can be attributed to the adsorption of the silica clusters between PVA molecular chains $[8,26]$.

The toughness of the PLA/silica samples increased from 3.6 to 5.6 MPa when the silica concentration was increased from 0 to $10 \mathrm{wt} \%$, implying the positive effect of the addition of $10 \mathrm{wt} \%$ filler on the toughness of the prepared sample, which is in agreement with the literature [67]. This improved toughness value corresponds to enhanced energy absorption ability. Enhanced toughening in the case of the addition of $10 \mathrm{wt} \%$ silica has also been reported in a previous study [77]. In addition, this behaviour can occur because the silica particles promote only partial stress within the PLA matrix, changing the direction of crack development [78-80]. The increase in toughness value until the filler concentration reaches a certain level (in this case, $15 \mathrm{wt} \%$ silica) followed by a decrease when the filler concentration is increased further can be explained based on the deboning mechanism. In this mechanism, voids are created between the silica/PLA interface, leading to shear yielding in the polymer matrix, which can only toughen the material to a certain level. As a result, agglomeration occurs beyond a certain filler content, resulting in defect points that 
adversely affect the mechanical properties [42,77]. The concentration and particle size of the filler can strongly contribute to the changes in mechanical properties, as reported in other studies of PLA/silica [81,82].

Nylon exhibited the largest decrease in toughness value, from $259 \mathrm{MPa}$ at $0 \mathrm{wt} \%$ to $50 \mathrm{MPa}$ at $15 \mathrm{wt} \%$. In addition to weak bonding at higher filler concentrations, the substantial increase in energy density owing to the addition of a filler, which can lead to the rapid degradation of the polymer, likely contributed to the decrease in the TS and toughness of the material [57].

The ductility of the material indicates the strain at the point of failure. The ability to deform plastically and adapt to the applied load is attractive in industrial applications that require high flexibility. Similar to the trend observed in the case of toughness, PP and nylon exhibit ductility values that are relatively greater than those of PVA and PLA (Figure 9).

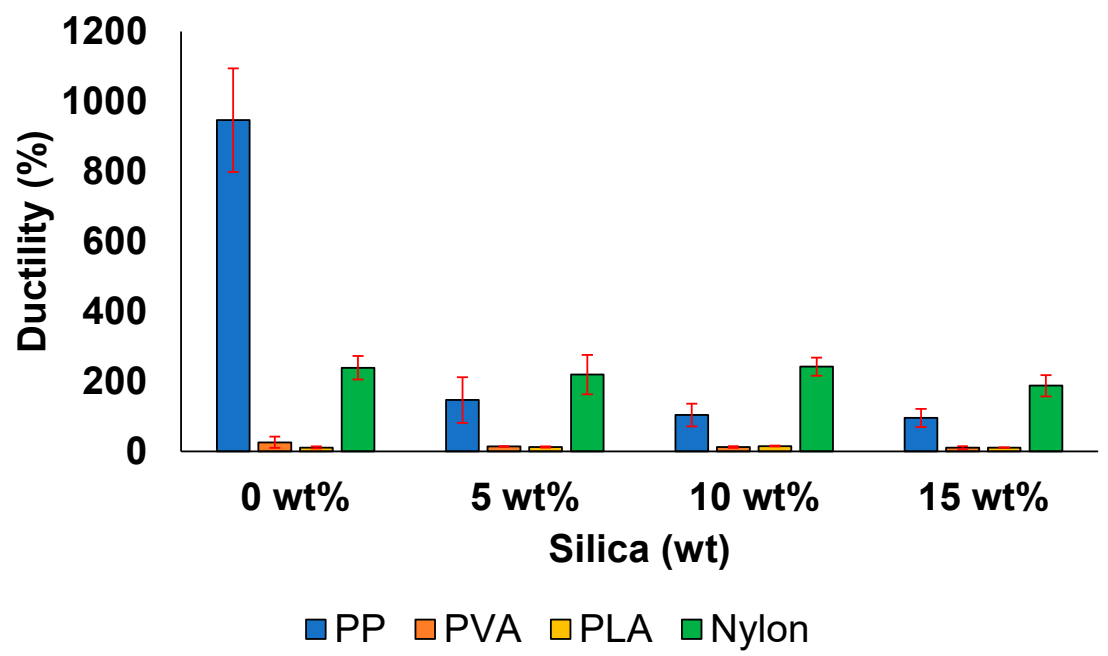

Figure 9. Ductility of the prepared samples.

In case of PP/silica samples, ductility decreased considerably (90\%) when the silica concentration was increased from 0 to $15 \mathrm{wt} \%$; the samples demonstrated a final elongation of $96 \%$. Further, the degradation behaviour is well associated with the development of structural voids and unexfoliated aggregates, reducing the ability of the matrix to exhibit enhanced ductility, as reported in other studies conducted on PP matrix systems [72].

A typical decrease in ductility values from $16 \mathrm{MPa}$ at $0 \mathrm{wt} \%$ to $10 \mathrm{MPa}$ at $15 \mathrm{wt} \%$ was observed in the prepared PVA/silica samples. Such a classic mechanical trend can be attributed to the non-homogeneous dispersion of the micro-sized silica in the polymer matrix and has been well documented in similar PVA/silica composite studies [8].

The ductility of the PLA sample prepared with $5 \mathrm{wt} \%$ silica increased by $13 \%$, whereas an increase of approximately $11 \%$ was reported previously [83]. Moreover, the sample exhibited the highest ductility (37.5\%) when considering the addition of $10 \mathrm{wt} \%$ filler, which corresponded to an elongation of $15.3 \%$ [67]. The ductility decreased by $2.1 \%$ at higher silica concentrations. The lower ductility values are reflected again by the stress concentrations at different locations because of the weakening effect of the agglomerates formed in the matrix [3].

Similar to the PP and PVA samples, the nylon samples exhibited a steady decrease in ductility with the increasing silica concentration. The ductility of the $0 \mathrm{wt} \%$ silica sample was $239 \%$, whereas that of the sample with $15 \mathrm{wt} \%$ silica was $188 \%$. This trend has also been observed in other studies [29]. The combination of a ductile polymer with short, brittle particles or fibers has been reported to result in lower strain values at the failure point compared with the strain values of neat polymers.

The elastic modulus (E) and yield stress associated with all the samples are shown in Figures 10 and 11. In the case of PP, E gradually decreased from $72 \mathrm{MPa}$ at $0 \mathrm{wt} \%$ to 
$41 \mathrm{MPa}$ at $15 \mathrm{wt} \%$. A similar behaviour was observed for its yield stress values (Figure 11). This decrease in mechanical property with the increasing filler amount is associated with the agglomerates in the filler matrix. Thus, stress concentrations are induced at several locations in the composite material, reducing the filler-aspect ratio. This further decreases the area available for forming a contact surface between the filler and matrix, leading to the formation of tactoids [72].

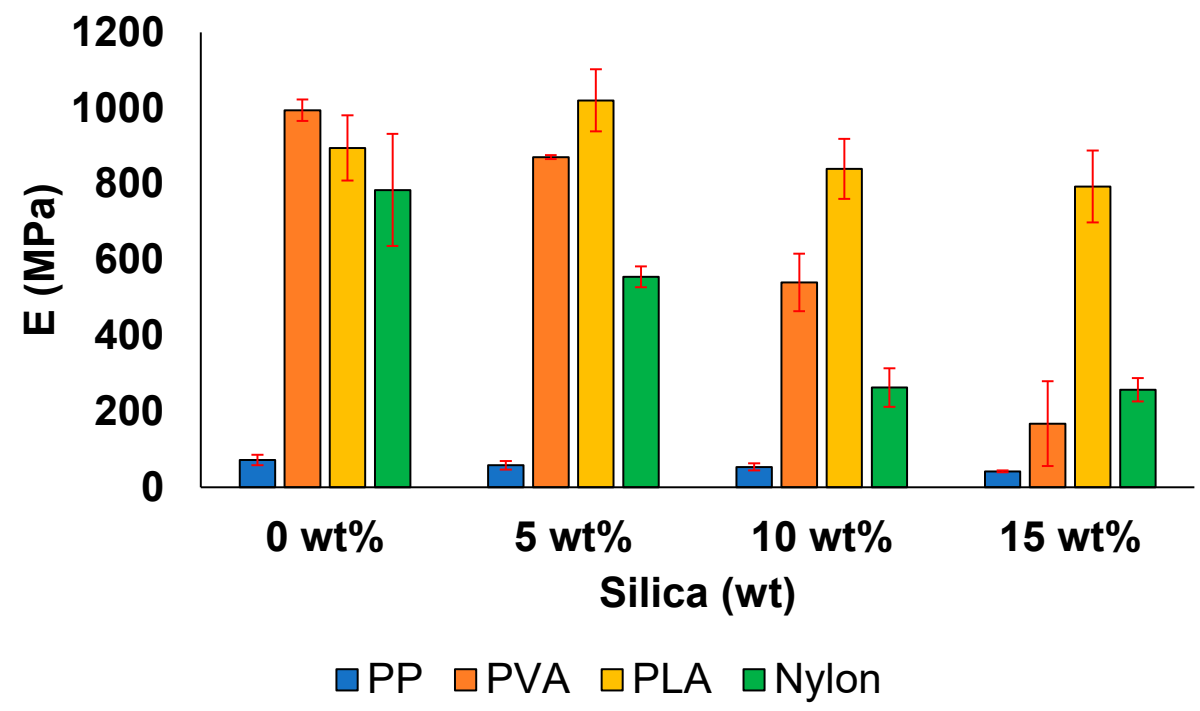

Figure 10. Elastic modulus of the prepared samples.

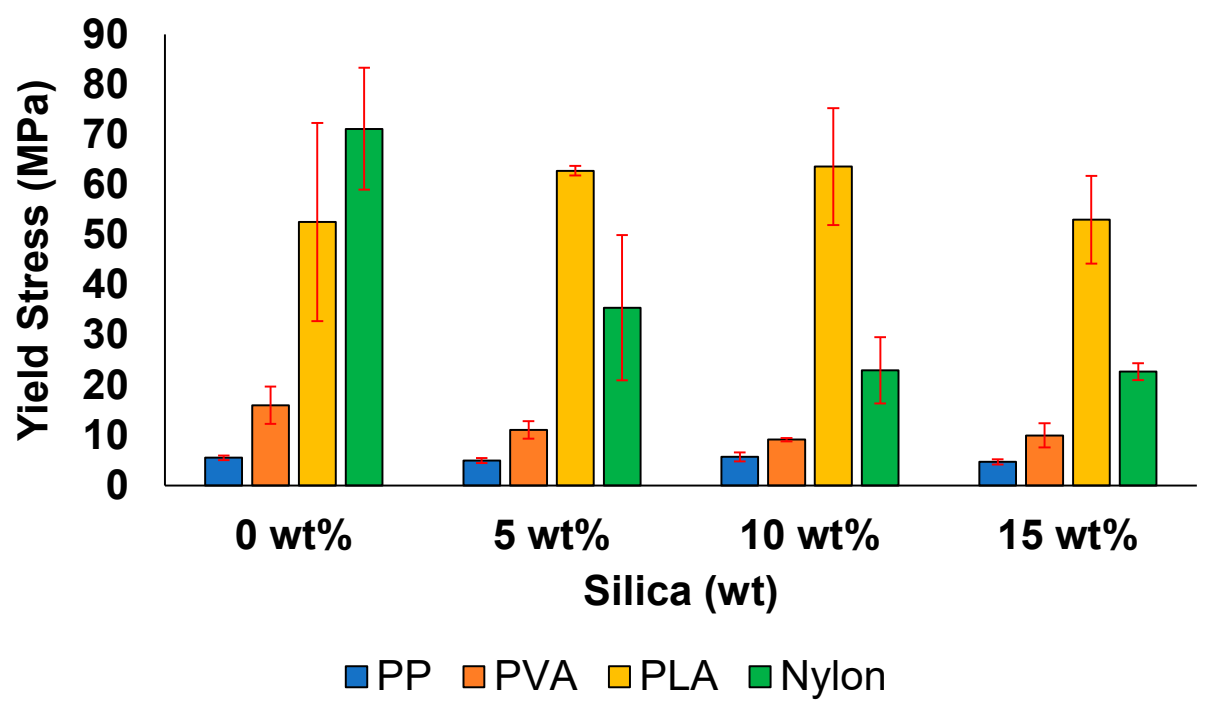

Figure 11. Yield stress of the prepared samples.

All the other samples exhibit a relatively higher E value and yield stress when compared with the samples prepared with PP. For instance, in case of PVA, the E values and yield stress decreased from 995 and $16 \mathrm{MPa}$ at $0 \mathrm{wt} \%$ to 167 and $10 \mathrm{MPa}$ at $15 \mathrm{wt} \%$, respectively. The inability to form stronger bonds with the addition of the filler leads to a decrease in the E value with the increasing silica content, which has also been previously reported [27].

In the case of the PLA, a noticeable increase was observed in the elastic modulus from $895 \mathrm{MPa}$ at $0 \mathrm{wt} \%$ to $1021 \mathrm{MPa}$ at $5 \mathrm{wt} \%$. The elastic modulus decreased at filler concentrations greater than $5 \mathrm{wt} \%$. In addition, one of the highest yield stress values was observed at the same filler concentration, i.e., approximately $63 \mathrm{MPa}$, which is at least $21 \%$ 
higher than the value reported for pure commercial PLA (49.5 MPa) [83]. The increase in the elastic modulus and yield stress values are positive effects of filler addition [67]. However, the decrease in both properties at higher silica concentrations is related to the agglomerate formation and uneven crystallization, resulting in weak bond formation.

The samples prepared with pure nylon exhibited the highest $\mathrm{E}$ and yield stress values among the samples investigated in this study. However, a decreasing trend in both mechanical properties was obtained when the filler concentration was increased from 0 to $15 \mathrm{wt} \%$. A reduction of almost $67 \%$ was observed with respect to both the elastic modulus and the yield stress value when the filler concentration was increased from 0 to $15 \mathrm{wt} \%$. This behaviour has been previously reported for nylon samples with silica concentrations from 2 to $10 \mathrm{wt} \%$, which has been attributed to the increasing stiffness and brittleness of the samples [56].

The mechanical properties of the prepared samples, except for the samples prepared with PLA, tended to diminish with increasing filler concentration. These diminished mechanical properties are likely a consequence of the uneven dispersion of the filler, which is mainly governed by the random mixing of silica particles during the extrusion procedure itself [81]. In addition, the irregular shape of the filler particles can result in such inconsistency during the mixing of the particles, which can further contribute to the non-homogeneous dispersion of particles and result in stress concentrations at various positions along with the samples, resulting in mechanical failure [82]. The mechanical properties of the prepared samples are presented in Table 2. The arithmetic mean was used to calculate the SD values, as shown in Equation (1):

$$
\mathrm{SD}=\sqrt{\left(\sum \mathrm{X}^{2}-\mathrm{n} \bar{X}^{2}\right) /(\mathrm{n}-1)},
$$

where $\mathrm{SD}$ is the estimated standard deviation, $\mathrm{X}$ is the measured value of a single reading, $\mathrm{n}$ is the number of measurements, and $\bar{X}$ is the arithmetic mean of a set of observed measurement values.

Table 2. Mechanical properties of all the prepared composite samples.

\begin{tabular}{|c|c|c|c|c|c|c|c|c|c|c|}
\hline PP/silica & $\begin{array}{c}\text { Tensile } \\
\text { Strength } \\
\text { (MPa) }\end{array}$ & SD & $\begin{array}{c}\text { Toughness } \\
\text { (MPa) }\end{array}$ & SD & $\underset{(\%)}{\text { Ductility }}$ & SD & $\begin{array}{l}\text { Elastic } \\
\text { Modulus } \\
(\mathrm{MPa})\end{array}$ & SD & $\begin{array}{l}\text { Yield Stress } \\
\text { (MPa) }\end{array}$ & SD \\
\hline 100:0 & 11 & \pm 1 & 95 & \pm 18 & 947 & \pm 148 & 72 & \pm 13 & 6 & \pm 0.5 \\
\hline $95: 5$ & 7 & \pm 1 & 33 & \pm 27 & 147 & \pm 65 & 58 & \pm 11 & 5 & \pm 0.5 \\
\hline 90:10 & 7 & \pm 1 & 8 & \pm 4 & 104 & \pm 32 & 53 & \pm 10 & 6 & \pm 0.9 \\
\hline $85: 15$ & 6 & \pm 0.8 & 6 & \pm 2 & 96 & \pm 26 & 41 & \pm 3 & 5 & \pm 0.6 \\
\hline \multicolumn{11}{|l|}{ PVA/silica } \\
\hline 100:0 & 54 & \pm 15 & 11 & \pm 8 & 26 & \pm 16 & 995 & \pm 28 & 16 & \pm 4 \\
\hline 95:5 & 76 & \pm 7 & 5 & \pm 0.7 & 14 & \pm 0.6 & 871 & \pm 5 & 11 & \pm 2 \\
\hline $90: 10$ & 30 & \pm 13 & 2 & \pm 0.5 & 13 & \pm 3 & 540 & \pm 76 & 9 & \pm 0.3 \\
\hline $85: 15$ & 31 & \pm 12 & 2 & \pm 1 & 11 & \pm 5 & 167 & \pm 112 & 10 & \pm 2 \\
\hline \multicolumn{11}{|c|}{ PLA/silica } \\
\hline 100:0 & 63 & \pm 7 & 4 & \pm 1 & 11 & \pm 3 & 896 & \pm 86 & 53 & \pm 20 \\
\hline $95: 5$ & 67 & \pm 4 & 5 & \pm 1 & 13 & \pm 2 & 1020 & \pm 82 & 63 & \pm 1 \\
\hline $90: 10$ & 121 & \pm 13 & 6 & \pm 1 & 15 & \pm 1 & 840 & \pm 79 & 64 & \pm 12 \\
\hline $85: 15$ & 54 & \pm 8 & 3 & \pm 0.4 & 11 & \pm 0.1 & 793 & \pm 95 & 53 & \pm 9 \\
\hline \multicolumn{11}{|c|}{ Nylon/silica } \\
\hline 100:0 & 120 & \pm 26 & 259 & \pm 30.60 & 239 & \pm 33 & 784.43 & \pm 148 & 71 & \pm 12 \\
\hline $95: 5$ & 46 & \pm 12 & 148.22 & \pm 39 & 220 & \pm 56 & 554.95 & \pm 27 & 35 & \pm 14 \\
\hline 90:10 & 26 & \pm 9 & 85.58 & \pm 36 & 243 & \pm 26 & 262.64 & \pm 51 & 23 & \pm 7 \\
\hline $85: 15$ & 23 & \pm 6 & 50.38 & \pm 14 & 188 & \pm 30.45 & 257 & \pm 30 & 22 & \pm 1 \\
\hline
\end{tabular}




\subsection{Thermal Characterization}

DSC analysis was carried out at a heating rate of $10^{\circ} \mathrm{C} / \mathrm{min}$ on all the prepared sets of composites to elucidate their crystallization behaviours. Figure 12 shows the melting peaks (Tm) obtained from the DSC thermograms. The observed Tm for pure PP is $135^{\circ} \mathrm{C}$, which is slightly lower than the value reported for PP [5]. The Tm for pure PVA is $171^{\circ} \mathrm{C}$, which is in agreement with the value reported in the literature [84]. For PLA, two melting peaks were observed at $145^{\circ} \mathrm{C}$ and $150^{\circ} \mathrm{C}$, consistent with the literature. These two peaks can be attributed to the coexistence of two PLA crystal structures known as the $\alpha$ and $\beta$ forms. The $\alpha$ form is the peak at a higher value because of the better quality and size of crystals [84]. A sharp peak is observed at $189^{\circ} \mathrm{C}$ in the thermogram of nylon [57]. A smooth transition temperature trend is observed for all the PLA samples, indicating that the pure PLA sample does not contain impurities. Furthermore, the addition of filler does not substantially change $\mathrm{Tm}$. The slight variations in the shapes of the curves are likely associated with the degree of crystallinity in each sample [25], implying that the overall thermal stability of the composite material is maintained.

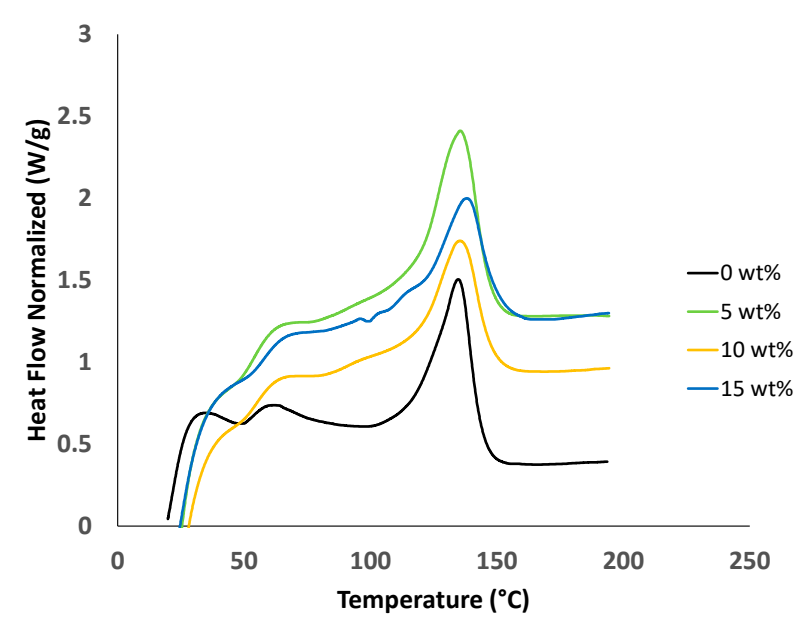

(a)

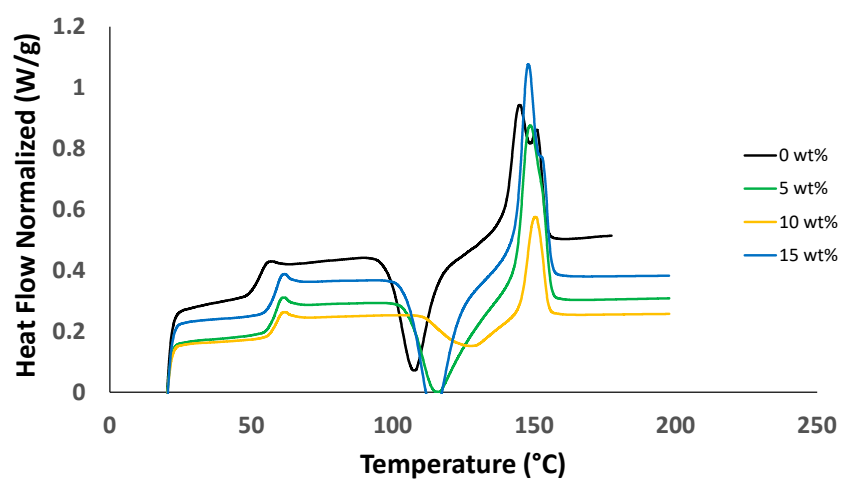

(c)

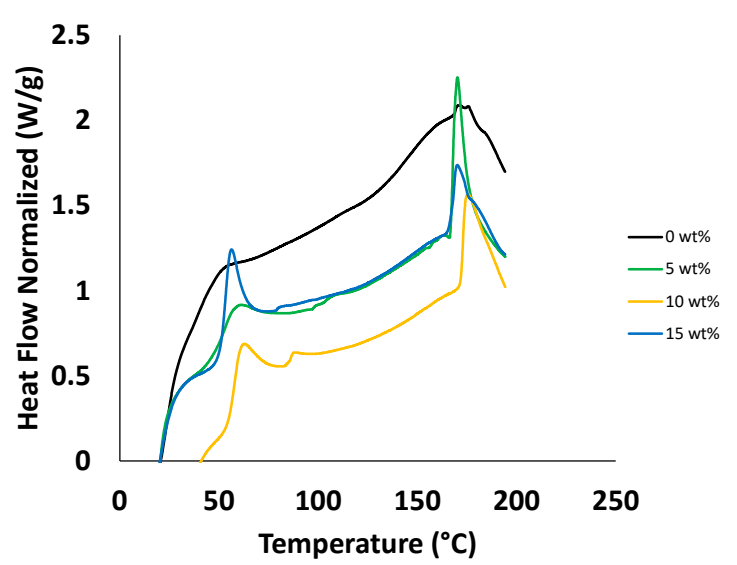

(b)

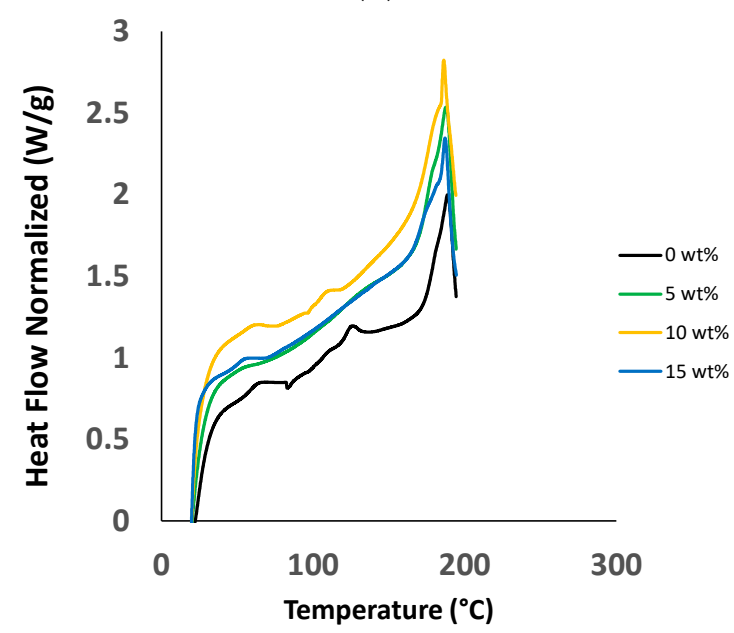

(d)

Figure 12. Melting peaks: (a) PP; (b) PVA; (c) PLA; and (d) Nylon.

The obtained DSC data were used to characterize the intrinsic thermal properties of the materials. For example, an increase in the filler concentration did not considerably affect the $\mathrm{Tm}$, glass-transition temperatures $(\mathrm{Tg})$, or crystallization temperatures $(\mathrm{Tc})$ of the samples. Once the $\mathrm{Tc}, \mathrm{Tg}$, and $\mathrm{Tm}$ values are determined, the range of processing temperatures can be identified, providing a reasonable estimation of the suitability of the materials for industrial 
applications. The most common industrial processing temperature is $\pm 40{ }^{\circ} \mathrm{C}[46,49]$. In addition, when the Tc and Tm values of the materials are known, the enthalpies of the materials can be estimated, providing an understanding regarding how much energy and heat would be required in the manufacturing process for such composite materials, which is an important consideration from the industrial manufacturing perspective. The Tg value for PP ranged from $41^{\circ} \mathrm{C}$ to $57^{\circ} \mathrm{C}$ (reaching a maximum at $10 \mathrm{wt} \%$ filler concentration), which is slightly lower than the values reported elsewhere [5]. In the case of PVA and PLA, the $\mathrm{Tg}$ values ranged from $44^{\circ} \mathrm{C}$ to $67^{\circ} \mathrm{C}$ and from $52^{\circ} \mathrm{C}$ to $58{ }^{\circ} \mathrm{C}$, respectively, as reported for other PVA and PLA systems [84], with the highest Tg values being observed for the samples with $15 \mathrm{wt} \%$ silica in both the cases. In case of nylon, the $\mathrm{Tg}$ varied from $31{ }^{\circ} \mathrm{C}$ to $42{ }^{\circ} \mathrm{C}$, with the highest value being obtained for the sample with $10 \mathrm{wt} \%$ silica. In any silica-containing sample, the Tg value of which increased compared with that of the pure polymer, silica particles may have prevented the thermal motion of the polymeric chains, resulting in the above phenomenon [27].

Slight variations in the Tc values and broadening and stretching during the crystallization process were observed in the case of samples containing silica. However, the added filler did not strongly affect the thermal characteristics of the composite materials, implying that they exhibit good thermal stability. The obtained results are consistent with previous studies involving various polymer/composite systems [85].

The areas under the cooling and heating curves were calculated to determine the enthalpies of crystallization and the melting enthalpies. The percent crystallinity was calculated as follows using Equation (2):

$$
\mathrm{X}_{\mathrm{c}}(\%)=\frac{\Delta \mathrm{H}_{\mathrm{m}}}{\Delta \mathrm{H}_{100 \%}(1-\theta)} \times 100 \%
$$

where $\mathrm{X}_{\mathrm{c}}$ is the percentage crystallinity of the pure polymer, $\Delta \mathrm{Hm}$ is the melting enthalpy, $\Delta \mathrm{H}_{100 \%}$ is the melting enthalpy of a $100 \%$ crystalline polymer $(170 \mathrm{~J} / \mathrm{g}$ for PP [5], $67 \mathrm{~J} / \mathrm{g}$ for PVA [25], 94 J/g for PLA [84], and $70 \mathrm{~J} / \mathrm{g}$ for nylon [86]), and $\theta$ is the mass fraction of the filler (sand).

The crystallinity values were observed to fluctuate mainly between $13 \%$ and $35 \%$ for all the prepared samples, consistent with the results of several previous polymer composite studies $[5,72,87]$. Overall, one concentration in each set resulted in a high crystallinity. However, the specific concentration that exhibited the highest crystallinity percentage varied from one system to another. In all cases, the decreasing crystallinity may be caused by the formation of imperfect crystals in the polymer because of the presence of silica interfering in the polymeric chains owing to random dispersion and incompatibility [84]. In addition, this variation could be attributed to the insufficient amount of filler present at the surface, causing the agglomeration or accumulation of the filler at the interface, where a soft layer is formed that tends to impede the nucleating effect $[21,88]$. The opposite is true in the case of an increase in crystallinity, wherein the silica particles are speculated to induce a heterogeneous nucleation effect [5]. The fluctuating variation in thermal properties, such as $\mathrm{Tc}, \Delta \mathrm{Hm}$, and $\mathrm{X}_{\mathrm{c}}$, can also be linked to the conformational changes of the macromolecular structures during the crystallization process because the filler was spread randomly and not densely packed, thereby weakening the molecular interactions of the structures. Such behavior has been reported in several composite studies in which the thermal values do not substantially vary $[72,88,89]$.

The $\mathrm{Tg}, \mathrm{Tc}, \mathrm{Tm}$, enthalpies of crystallization $(\Delta \mathrm{Hc}), \Delta \mathrm{Hm}$, and $\mathrm{X}_{\mathrm{c}}$ values for all the prepared composite materials are presented in Table 3. 
Table 3. Thermal properties of all the prepared samples.

\begin{tabular}{|c|c|c|c|c|c|c|}
\hline PP/silica & $\operatorname{Tg}\left({ }^{\circ} \mathrm{C}\right)$ & $\operatorname{Tc}\left({ }^{\circ} \mathrm{C}\right)$ & $\operatorname{Tm}\left({ }^{\circ} \mathrm{C}\right)$ & $\Delta H_{c}(\mathrm{~J} / \mathrm{g})$ & $\Delta \mathrm{Hm}(\mathrm{J} / \mathrm{g})$ & $X_{c}(\%)$ \\
\hline 100:0 & 54.1 & 89.1 & 134.8 & 39.2 & 27.7 & 16.3 \\
\hline 95:5 & 55.0 & 89.2 & 135.4 & 50.0 & 44.0 & 25.9 \\
\hline $90: 10$ & 57.0 & 89.0 & 135.4 & 5.7 & 24.2 & 14.2 \\
\hline $85: 15$ & 41.1 & 88.9 & 138.0 & 29.6 & 24.1 & 14.1 \\
\hline \multicolumn{7}{|l|}{ PVA/silica } \\
\hline 100:0 & 43.6 & 136.3 & 170.6 & 15.7 & 23.2 & 34.6 \\
\hline $95: 5$ & 52.0 & 135.5 & 170.1 & 10.2 & 14.0 & 20.9 \\
\hline $90: 10$ & 58.0 & 133.0 & 175.3 & 13.4 & 12.8 & 19.1 \\
\hline $85: 15$ & 66.8 & 135.1 & 170.0 & 12.8 & 19.2 & 28.6 \\
\hline \multicolumn{7}{|l|}{ PLA/silica } \\
\hline 100:0 & 52.1 & 107.9 & 144.9 & 33.0 & 25.6 & 27.3 \\
\hline $95: 5$ & 57.6 & 116.4 & 148.6 & 35.4 & 30.0 & 31.9 \\
\hline 90:10 & 57.0 & 128.1 & 150.4 & 15.1 & 13.7 & 14.5 \\
\hline $85: 15$ & 57.7 & 115.1 & 147.9 & 49.9 & 31.3 & 33.3 \\
\hline \multicolumn{7}{|c|}{ Nylon/silica } \\
\hline 100:0 & 31.1 & 149.4 & 188.6 & 56.1 & 11.1 & 15.8 \\
\hline $95: 5$ & 36.9 & 150.1 & 187.7 & 20.1 & 19.4 & 27.7 \\
\hline $90: 10$ & 41.6 & 151.0 & 186.1 & 27.4 & 17.5 & 24.9 \\
\hline $85: 15$ & 36.4 & 151.6 & 187.1 & 27.6 & 18.6 & 26.6 \\
\hline
\end{tabular}

\subsection{SEM Characterization}

The morphologies of the neat polymer sheets and reinforced composite sheet materials are shown in the SEM images in Figures 13-16 for PP, PVA, PLA, and nylon, respectively. Generally, a smooth surface was observed for all the neat polymer samples, consistent with several previous polymer/composite studies $[8,21]$. The SEM images of the silica reinforcements at concentrations ranging from 5 to $15 \mathrm{wt} \%$ confirm the random dispersion of silica particles in the corresponding matrices in all the prepared samples. The SEM images show that the silica particles are spherically shaped, as previously reported [1]. Moreover, the photos show that the particle density and extent of agglomeration increased with increasing filler concentration. When agglomeration begins, the mechanical and thermal properties are adversely affected, reflected in the experimental results reported in the literature [21].

In case of the PP/silica samples, a smooth surface is observed at $0 \mathrm{wt} \%$ silica. An increase in the number of randomly dispersed silica particles can be observed on the surface of the samples with 5 and $10 \mathrm{wt} \%$ silica, as evident in Figure 13b,c, respectively. Clumped particles are observed on the surface of the sample with $15 \mathrm{wt} \%$ silica (Figure 13d), indicating agglomeration. Similar behavior has been reported for PP/silica composites with similar silica loadings [90]. For PVA, increased dispersion is observed with increasing silica loading from 0 to $10 \mathrm{wt} \%$ (Figure 14a-c). For the samples prepared with PLA, good dispersion is observed at 5 and $10 \mathrm{wt} \%$ silica loadings (Figure $15 b, c$, respectively). The excellent distribution in these samples reflects the enhanced properties at these concentrations. At $15 \mathrm{wt} \%$ silica (Figure 15d), larger particles begin to appear at greater distances from each other. These particles correspond to agglomerates. A similar trend of random dispersion is also observed in the samples prepared from nylon (Figure 16). In addition, the SEM images indicate that in all of the samples, the particles are just settled in the matrix and not homogeneously mixed or well bonded to the matrix. The interaction and adhesion of the 
particles with the matrix are properties that require further study because they can strongly affect the enhanced mechanical and thermal behaviors of composite materials.
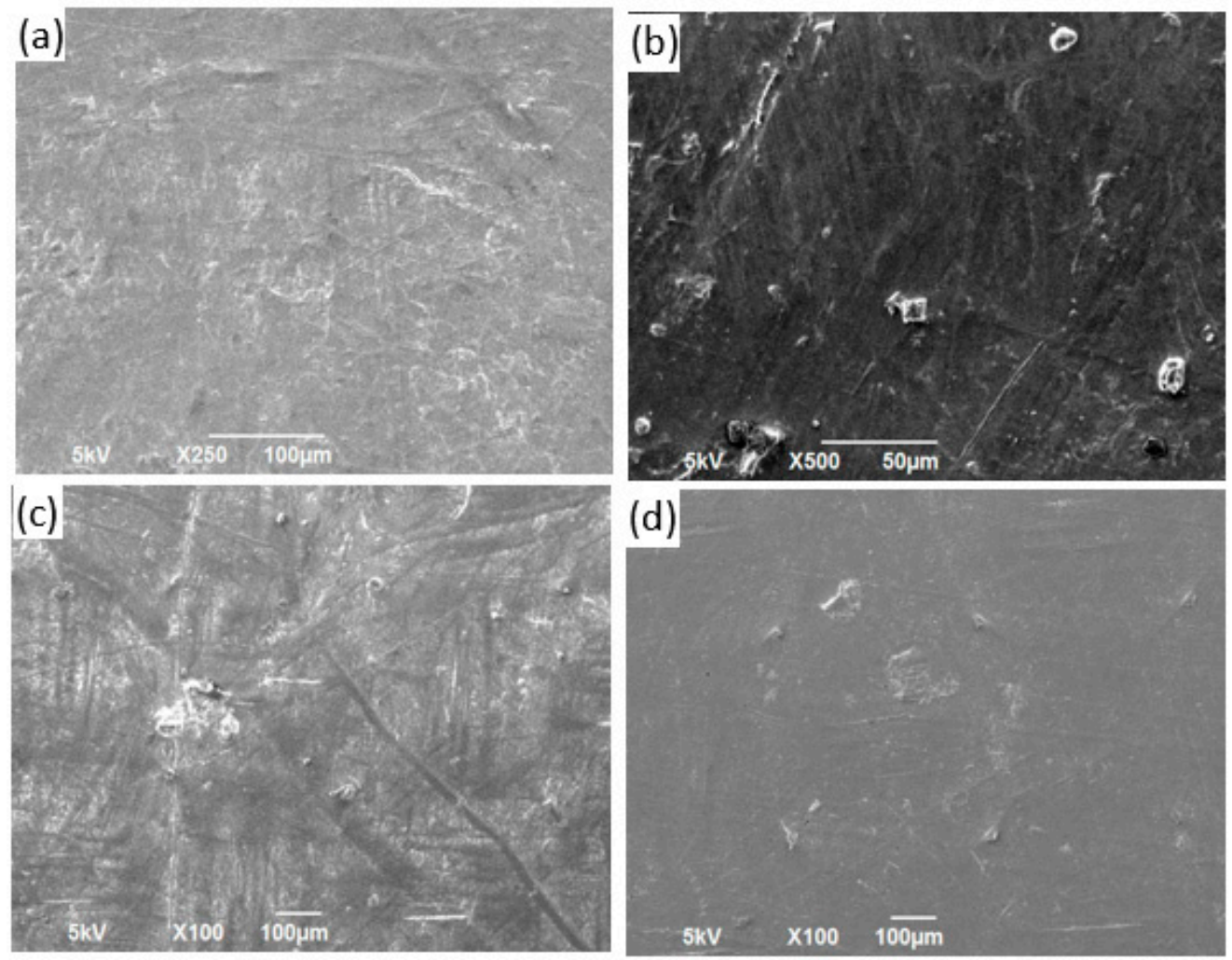

Figure 13. Images obtained using an SEM for PP/silica samples containing (a) $0 \mathrm{wt} \%$, (b) $5 \mathrm{wt} \%$, (c) $10 \mathrm{wt} \%$, and (d) $15 \mathrm{wt} \%$ silica.
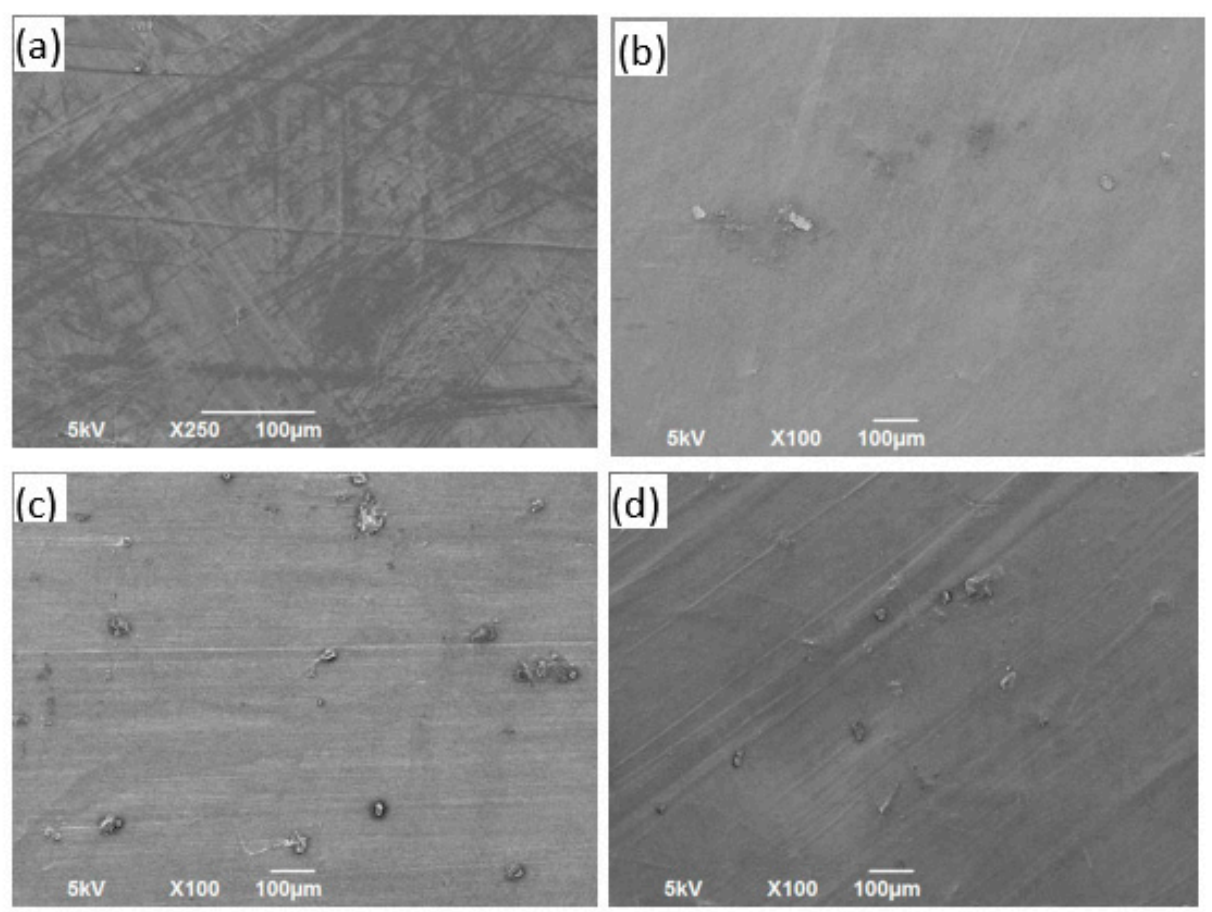

Figure 14. Images obtained using an SEM for PVA/silica samples containing (a) $0 \mathrm{wt} \%$, (b) $5 \mathrm{wt} \%$, (c) $10 \mathrm{wt} \%$, and (d) $15 \mathrm{wt} \%$ silica. 

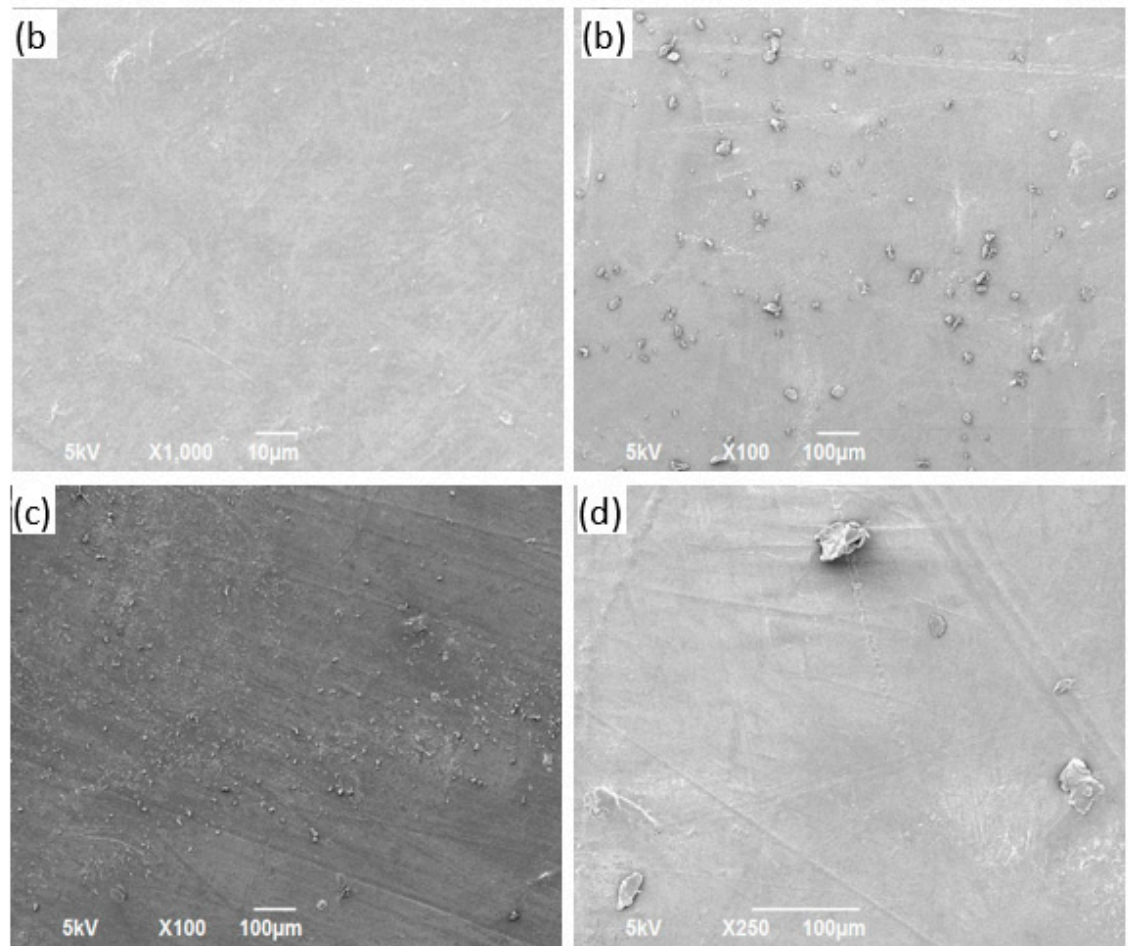

Figure 15. Images obtained using an SEM for PLA/silica samples containing (a) $0 \mathrm{wt} \%$, (b) $5 \mathrm{wt} \%$, (c) $10 \mathrm{wt} \%$, and (d) $15 \mathrm{wt} \%$ silica.
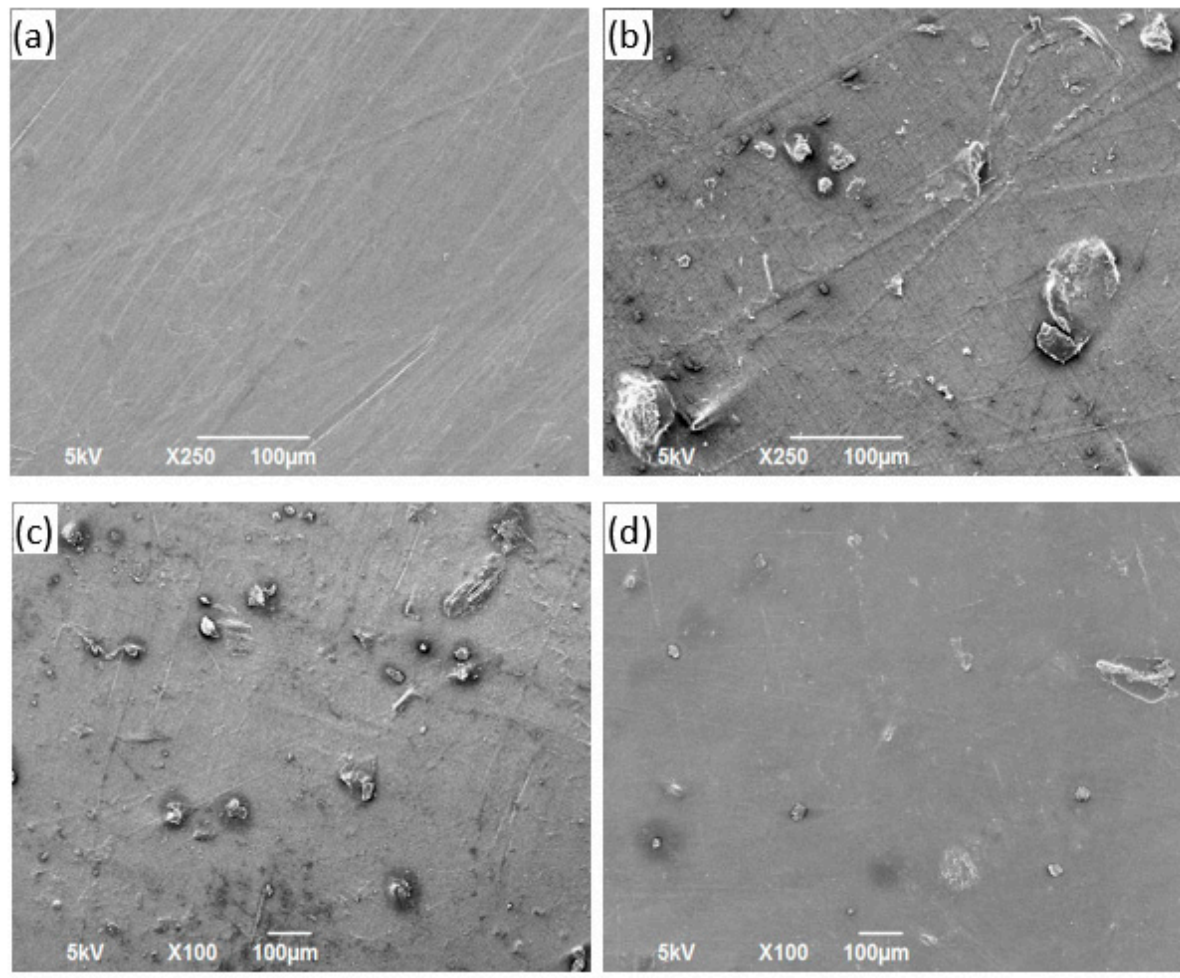

Figure 16. Images obtained using an SEM for Nylon/silica samples containing (a) $0 \mathrm{wt} \%$, (b) $5 \mathrm{wt} \%$, (c) $10 \mathrm{wt} \%$, and (d) $15 \mathrm{wt} \%$ silica.

\subsection{Bulk Density}

The procedure specified in ASTM D7263-09 was followed to determine the dry density of the silica filler used in this study [91]. The sand sample was dried using an electric 
drying oven and a controlled drying process. The density of the filler was calculated using Equation (3) [92]:

$$
\rho_{\text {filler }}=\frac{m_{\text {filler }}}{V}
$$

where $\rho_{\text {filler }}$ is the density of the filler in $\mathrm{kg} / \mathrm{m}^{3}, \mathrm{~m}_{\text {filler }}$ is the mass of the filler in $\mathrm{kg}$, and $V$ is the volume of the measuring cylinder in $\mathrm{m}^{3}$.

The apparent densities of the polymers were determined according to ASTM D792-20 [93]. After the masses of the samples in air and water were measured, their corresponding apparent densities can be calculated using Equation (4) [92]:

$$
\rho_{\text {polymer }}=\frac{\mathrm{m}_{\text {air }} \rho_{\text {water }}}{\mathrm{m}_{\text {air }}+\mathrm{m}_{\mathrm{water}}}
$$

where $\rho_{\text {polymer }}$ is the apparent density of polymer in $\mathrm{kg} / \mathrm{m}^{3}, \mathrm{~m}_{\text {air }}$ is the mass of the sample measured in air in $\mathrm{kg}, \mathrm{m}_{\text {water }}$ is the mass of the sample measured in water in $\mathrm{kg}$, and $\rho_{\text {water }}$ is the density of water in $\mathrm{kg} / \mathrm{m}^{3}$.

To estimate the density of the composite material, the theoretical density of the composite material was first estimated using the linear rule of mixing, which assumes that the composite property is the volume-weighted average of the matrix and dispersed phases. This equation also assumes that there is no inclusion of air in the composite material and that the filler does not affect the density of the polymeric matrix by inducing nucleation or crystal formation. Equation (5) was used to calculate the density of the composite material [94]:

$$
\rho_{\mathrm{c}}=\frac{\rho_{\text {filler }} \rho_{\text {matrix }}}{\rho_{\text {matrix }} \mathrm{m}_{\text {filler }}+\rho_{\text {filler }}\left(1-\mathrm{m}_{\text {filler }}\right)}
$$

where $\rho_{\mathrm{c}}$ is the density of the composite in $\mathrm{kg} / \mathrm{m}^{3}, \rho_{\text {filler }}$ is the density of the filler (silica) in $\mathrm{kg} / \mathrm{m}^{3}, \rho_{\text {matrix }}$ is the density of the polymer matrix (i.e., PP, PVA, PLA, and nylon) in $\mathrm{kg} / \mathrm{m}^{3}$, and $\mathrm{m}_{\text {filler }}$ is the mass fraction of the filler in $\mathrm{kg}$.

A precise weighing balance (Citizen-CX 220, d $0.0001 \mathrm{~g}$, CITIZEN SCALE PVT. LTD, Mumbai, India) was used to measure the weight of the composite materials. For the volume measurements, the prepared samples were cut with a cutter according to ASTM D6287-17 [95]. The thickness of each sample was measured along five different points using a Mitutoyo thickness gage (model 547-526S) to ensure uniformity. The data collected from the weighing balance and thickness gage were used to estimate the experimental bulk densities of the samples by calculating their corresponding mass-to-volume ratios.

\section{Discussion}

The selected samples were subjected to tensile testing in accordance with ASTM 638. The tensile strength (TS) of the prepared samples was calculated by dividing the maximum applied load with the average cross-sectional area of the gage length of the specimen, as shown in Equation (6):

$$
\mathrm{TS}[\mathrm{MPa}]=\frac{\mathrm{F}_{\max }}{A}
$$

where TS is the tensile strength in $\mathrm{MPa}, \mathrm{F}_{\max }$ is the maximum force exerted on the specimen under tension in $\mathrm{N}$, and $A$ is the average cross-sectional area of the sample in $\mathrm{mm}^{2}$.

Further, the elastic modulus was estimated by extending the linearity of the loadextension plot and dividing the difference between the stress values at any given corresponding point of the specified segment on this line with its corresponding difference in strain values according to Equation (7). In addition, the modulus of elasticity was calculated based on the average initial cross-sectional area concerning the gage length. However, for any sample for which no proportionality was observed, the corresponding secant value was estimated by forming a tangent line and noting the respective strain value from the yield point at which the tangent passes through the zero-stress value. The individual stress 
value used in the computation was then defined by dividing the initial load-extension curve with the actual average cross-sectional area of the prepared sample:

$$
\mathrm{E}[\mathrm{MPa}]=\frac{\mathrm{F} \times \mathrm{L}_{\text {original }}}{\mathrm{A} \times \Delta \mathrm{L}}
$$

where $\mathrm{E}$ is the elastic modulus in $\mathrm{MPa}, \mathrm{F}$ is the force exerted on the specimen under tension in $\mathrm{N}, \mathrm{L}_{\text {original }}$ is the original gauge length of the sample in $\mathrm{mm}, \mathrm{A}$ is the original crosssectional area of the specimen in $\mathrm{mm}^{2}$, and $\Delta \mathrm{L}$ is the change in length of the specimen in $\mathrm{mm}$.

Elongation is useful when considering uniform deformation with respect to the gage length of the sample. Elongation values are quantitatively crucial for realizing good engineering designs. In addition, when the sample undergoes necking (nonuniform deformation) along the gage length, the corresponding nominal strain values are measured. Further, based on the observed elongation, the extension of the sample at the final point of rupture can be divided with the initial gage length and multiplied by 100 to prevent stretching at break (strain at failure or ductility).

The ductility of the samples can be calculated as follows:

$$
\text { Ductility }(\%)=\frac{\mathrm{L}_{\text {final }}-\mathrm{L}_{\text {original }}}{\mathrm{L}_{\text {original }}} \times 100
$$

where $\mathrm{L}_{\text {original }}$ is the original gage length of the specimen in $\mathrm{mm}$ and $\mathrm{L}_{\text {final }}$ is the final length at break of the specimen in $\mathrm{mm}$.

The toughness of a material indicates the amount of energy that it can absorb on impact and can be estimated by determining the area under the stress-strain plot. The toughness can be calculated as follows:

$$
\text { Toughness }[\mathrm{MPa}]=\sigma \times \varepsilon
$$

where $\sigma$ is the stress in $\mathrm{N}$ and $\varepsilon$ is the strain.

The yield stress values of the specimens can be determined by marking the intersection point of the $0.2 \%$ offset stress values in the original stress-strain plot.

Through this study, the significant impact of silica on different polymeric waste was established and studied. Furthermore, when silica was added to polymeric waste, the mechanical, thermal, and bulk density properties of the material can be altered according to the application requirements [30]. Herein, composite sheets with different polymers blended with various amounts of silica were successfully prepared via melt blending and hot compression molding. The TS of the developed composite materials increased with increasing filler concentration to $5 \mathrm{wt} \%$ in the case of PVA. In contrast, in the case of PP/silica and PLA/silica samples, the peak values corresponded to $10 \mathrm{wt} \%$ filler. This higher optimum filler content reflects the enhanced mechanical properties imparted by silica reinforcement. In all the developed samples, the values of other mechanical properties (e.g., toughness, ductility, elastic modulus, and yield stress) decreased when the filler content exceeded a certain level, indicating a weakening of the matrix owing to agglomeration. Among the thermal properties, the melting temperatures and glass-transition temperatures did not substantially vary, promoting the thermal stability of the developed composite material with increasing filler addition. Moreover, the crystallinity varied from $14 \%$ to $35 \%$ in all cases, corresponding to the random dispersion of the particles at various weight percentages of silica. SEM analysis showed that the particles are dispersed randomly and non homogeneously, which is a property that must be improved to further enhance the properties of the composites. For the bulk density, a decreasing trend was observed in all the polymeric samples with an increasing concentration of silica particles. This trend is advantageous for industrial applications because a low density facilitates the easy handling and transportation of composite materials. 
Generally, the composite density decreased with the increasing filler concentration, except in case of the PP theoretical data, which indicated the opposite behavior. This may be linked to be the fact that the density of the filler $\left(1047 \mathrm{~kg} / \mathrm{m}^{3}\right)$ was lower than that of the polymers. The case in which the density increased with increasing filler concentration is explained by the dispersion of the filler. In the case of PP, the density varied from 788 to $826 \mathrm{~kg} / \mathrm{m}^{3}$ as the filler concentration was varied from 0 to $15 \mathrm{wt} \%$, respectively. In the PVA samples, the density decreased from $1142 \mathrm{~kg} / \mathrm{m}^{3}$ to $1057 \mathrm{~kg} / \mathrm{m}^{3}$ as the filler content was increased from 0 to $15 \mathrm{wt} \%$, respectively. For PLA, other researchers have reported a steady decreasing density trend, including a 9.8\% decrease at $0 \mathrm{wt} \%$ and $26.2 \%$ decrease at $15 \mathrm{wt} \%$ [67]. Similarly, for nylon, a decrease of $10 \%$ was observed at $0 \mathrm{wt} \%$ along with a reduction of $17 \%$ at $15 \mathrm{wt} \%$. Such variations are speculated to be caused by formation of air pockets during the process attributed to the the high temperatures applied when processing the samples that would affect the density. In addition, because of poor mixing, residual moisture can be degassed within the material during the processing phase, further decreasing the material's density because of the high viscosities achieved by the polymeric matrix $[94,96]$. From an industrial perspective, using fillers to decrease the densities of polymers is potentially helpful in developing composite materials that float [97]. Furthermore, decreasing the densities for such composite materials enables the material to be handled more efficiently, which can be considered as an essential design parameter to reduce the costs involved with transportation [98]. Table 4 presents the theoretical and experimental data for bulk densities, and Figure 17 shows a comparison between the theoretical and practical densities of all the prepared composite materials. The properties observed in this study confirm the effect of silica as a filler. Further experiments are underway to study the same systems using a suitable compatibilizer to characterize the effect of an additional agent on the behavior of the composite materials, which could potentially enhance the interaction and integrity of the filler-polymer matrices. Such a mechanochemical study would aid in understand the 3D printing capability of such materials and expand the possibility of reusing the silica/waste polymer materials in 3D printing technology $[31,99]$ and to avoid the possible failure mechanism that could be caused by 3D Printing [100].

Table 4. Theoretical and experimental composite bulk densities for all the prepared samples.

\begin{tabular}{|c|c|c|}
\hline PP/silica & Theoretical Density $\left(\mathrm{kg} / \mathrm{m}^{3}\right)$ & Experimental Density $\left(\mathrm{kg} / \mathrm{m}^{3}\right)$ \\
\hline 100:0 & 1050 [101] & 787.50 \\
\hline $95: 5$ & 1049.88 & 800.05 \\
\hline 90:10 & 1049.75 & 810.42 \\
\hline $85: 15$ & 1499.24 & 825.50 \\
\hline \multicolumn{3}{|l|}{ PVA/silica } \\
\hline 100:0 & $1290[98]$ & 1141.90 \\
\hline 95:5 & 1275.24 & 1116.32 \\
\hline $90: 10$ & 1260.82 & 1086.74 \\
\hline $85: 15$ & 1755.77 & 1057.16 \\
\hline \multicolumn{3}{|l|}{ PLA/silica } \\
\hline 100:0 & $1250[83]$ & 1126.89 \\
\hline $95: 5$ & 1238.04 & 1062.38 \\
\hline 90:10 & 1226.30 & 974.98 \\
\hline $85: 15$ & 1714.70 & 896.00 \\
\hline \multicolumn{3}{|c|}{ Nylon/silica } \\
\hline $100: 0$ & 1350 [98] & 1020.50 \\
\hline $95: 5$ & 1330.79 & 992.94 \\
\hline 90:10 & 1312.11 & 965.37 \\
\hline $85: 15$ & 1816.20 & 937.81 \\
\hline
\end{tabular}



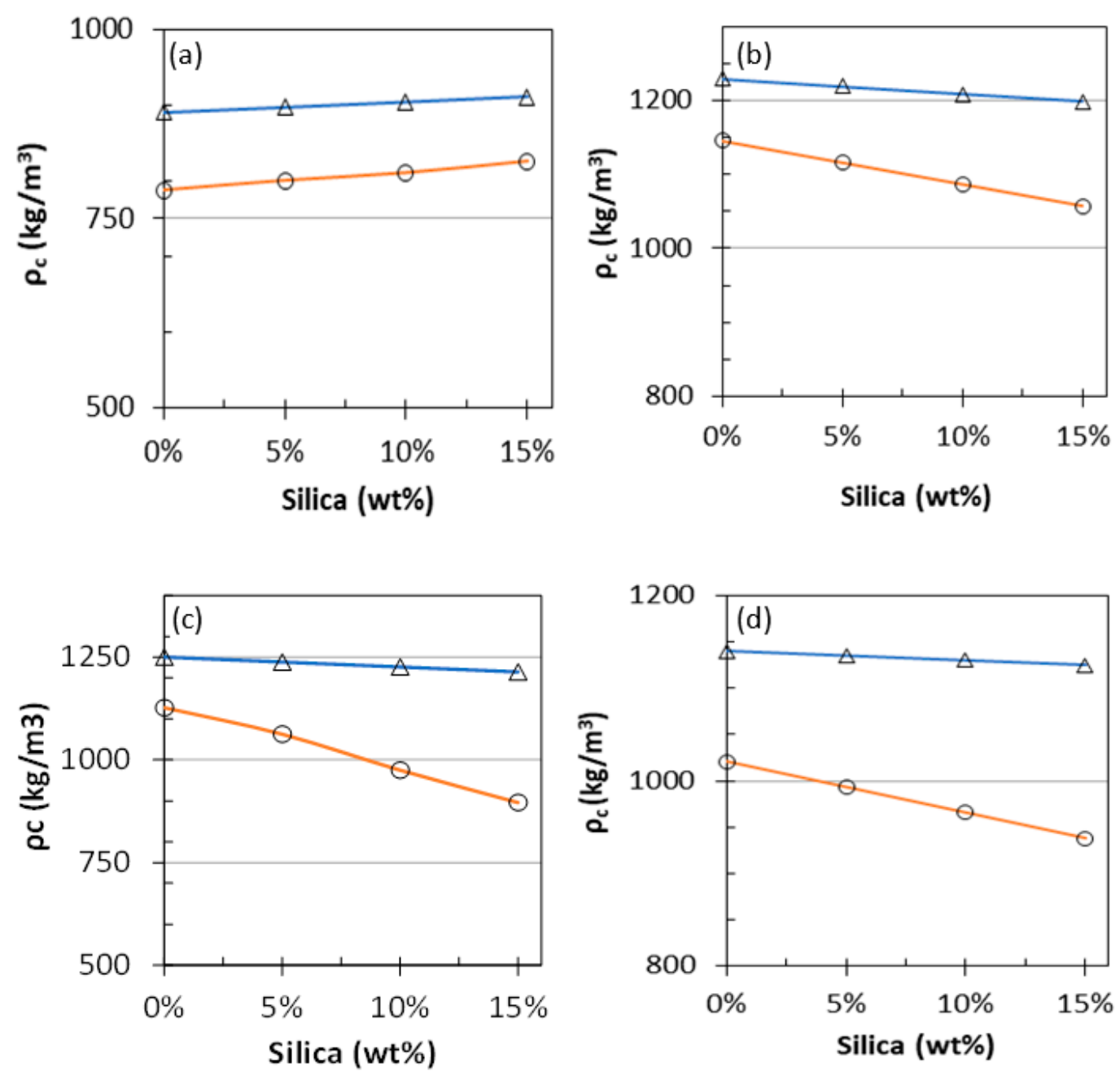

$\triangle$ Theoretical composite density

- Experimental composite density

Figure 17. Theoretical and experimental composite bulk densities of (a) PP/silica, (b) PVA/silica, (c) PLA/silica, and (d) nylon/silica composites.

\section{Conclusions}

In general, the tensile strength is improved due to mixing silica into the polymeric waste from 3D printing. For PLA, this increase was up to $10 \%$, whereas the impact on PP mixtures was insignificant, on the contrary the increase in the strength to $5 \%$ was observed for PVA and nylon. On the other hand, for all polymeric mixtures, the toughness dropped due to the increase silica percentage, and a similar observation was concluded for the ductility. Moreover, a noticeable decrease in the modulus of the elasticity was observed as the silica percentages increased, and the same trend was observed for the yield strength, except for the PLA. A consistent decrease in the density of the silica/polymers mixtures was observed more silica was added, except for the PP that showed a slight increase.

In general, it has been reported that recycling polymeric waste of the 3D printing process will affect different aspects of the properties of the 3D printed parts like shear stress, temperature, and oxygen contents that occur during extrusion and degrade extruded polymers [102]. Moreover, the process takes place not only in polymers sensitive to these factors but also in polymers that are relatively resistant [100] in addition to the fact the changes in the physical properties of the polymer significantly influence the manufacture of high-quality extrusion products. It has been found that multiple extrusiona of polymers have a strong influence on their change in viscosity, molecular weight, and breaking 
strength, where changes in properties are generated by factors such as temperature, but also by the amount of extrusion of one material [103]. Ultimately, additive manufacturing becoming a valuable tool for many industries as equivalent and subtractive manufacturing processes [104].

Author Contributions: Conceptualization, W.A. and S.S.; methodology, W.A.; validation, A.H.A.-M., W.A. and S.S.; investigation, A.H.A.-M.; resources, W.A.; data curation, S.S.; writing-original draft preparation, A.H.A.-M.; writing-review and editing, A.H.A.-M.; supervision, W.A.; project administration, A.H.A.-M.; funding acquisition, W.A. All authors have read and agreed to the published version of the manuscript.

Funding: This research was funded by UAE University, Grant number G003334, 2019/2021.

Institutional Review Board Statement: Not applicable.

Informed Consent Statement: Not applicable.

Data Availability Statement: Not applicable.

Acknowledgments: The authors would like to acknowledge the Research Office at UAE University to sponsor the project.

Conflicts of Interest: The authors declare no conflict of interest.

\section{References}

1. Turku, I.; Kasala, S.; Kärki, T. Characterization of Polystyrene Wastes as Potential Extruded Feedstock Filament for 3D Printing. Recycling 2018, 3, 57. [CrossRef]

2. Hanifpour, A.; Bahri-Laleh, N.; Nekoomanesh-Haghighi, M.; Karimi, M. Synthesis and Characterization of Poly1-Hexene/Silica Nanocomposites. Polym. Test. 2017, 61, 27-34. [CrossRef]

3. Bouafif, H.; Koubaa, A.; Perré, P.; Cloutier, A.; Riedl, B. Wood Particle/High-Density Polyethylene Composites: Thermal Sensitivity and Nucleating Ability of Wood Particles. J. Appl. Polym. Sci. 2009, 113, 593-600. [CrossRef]

4. Wang, B.; Ma, H.; Wu, D.; Zhu, L.; Jin, Z. Toughening polypropylene by tiny amounts of fillers. Pigment. Resin Technol. 2017, 46, 309-317. [CrossRef]

5. Srisawat, N.; Nithitanakul, M.; Srikulkit, K. Spinning of fibers from polypropylene/silica composite resins. J. Compos. Mater. 2011, 46, 99-110. [CrossRef]

6. Preto, M.; Tavares, M.I.B.; Da Silva, E.P. Low-field NMR study of Nylon 6/silica composites. Polym. Test. 2007, 26, 501-504. [CrossRef]

7. Siraj, S.; Al Marzouqi, A.; lqbal, M.Z. Mechanical and wettability performance of sand/hdpe composite sheets. Mater. Sci. Forum. 2020, 1015, 9-14. [CrossRef]

8. Kotoky, T.; Dolui, S.K. Synthesis and Characterisation of Polyvinyl Alcohol (PVA)/Silica Hybrid Composites Derived Through the Sol-Gel Method in Aqueous Medium: Effect of Acid Content, Silica Content and Viscosity of PVA on the Dispersion Characteristics of Silica and the Physical Properties of the Composites. J. Sol. Gel Sci. Technol. 2004, 29, 107-114.

9. Niaounakis, M. Recycling of Biopolymers--The Patent Perspective. Eur. Polym. J. 2019, 114, 464-475. [CrossRef]

10. Hedayati, F.; Moshiri-Gomchi, N.; Assaran-Ghomi, M.; Sabahi, S.; Bahri-Laleh, N.; Mehdipour-Ataei, S.; Mokhtari-Aliabad, J.; Mirmohammadi, S.A. Preparation and properties of enhanced nanocomposites based on PLA/PC blends reinforced with silica nanoparticles. Polym. Adv. Technol. 2019, 31, 566-573. [CrossRef]

11. Tian, X.; Liu, T.; Wang, Q.; Dilmurat, A.; Li, D.; Ziegmann, G. Recycling and remanufacturing of 3D printed continuous carbon fiber reinforced PLA composites. J. Clean. Prod. 2017, 142, 1609-1618. [CrossRef]

12. Brostow, W.; Datashvili, T.; Jiang, P.; Miller, H. Recycled HDPE Reinforced with Sol-Gel Silica Modified Wood Sawdust. Eur. Polym. J. 2016, 76, 28-39. [CrossRef]

13. Ahmed, W.; Khenata, R.; Siraj, S.; Al-Douri, Y. Ionic Liquid Potential to Recycle Polymeric Waste: An Experimental Investigation. Mater. Res. 2020, 23. [CrossRef]

14. Zulkifli, N.I.; Samat, N.; Anuar, H.; Zainuddin, N. Mechanical properties and failure modes of recycled polypropylene/microcrystalline cellulose composites. Mater. Des. 2015, 69, 114-123. [CrossRef]

15. La Rosa, A.D.; Blanco, I.; Banatao, D.R.; Pastine, S.J.; Björklund, A.; Cicala, G. Innovative Chemical Process for Recycling Thermosets Cured with Recyclamines by Converting Bio-Epoxy Composites in Reusable Thermoplastic-An LCA Study. Materials 2018, 11, 353. [CrossRef] [PubMed]

16. Utekar, S.; Suriya, V.K.; More, N.; Rao, A. Comprehensive Study of Recycling of Thermosetting Polymer Composites-Driving Force, Challenges and Methods. Compos. Part B Eng. 2021, 207, 108596. [CrossRef]

17. Monti, M.; Scrivani, M.T.; Gianotti, V. Effect of SEBS and OBC on the Impact Strength of Recycled Polypropylene/Talc Composites. Recycling 2020, 5, 9. [CrossRef] 
18. Zhong, S.; Rakhe, P.; Pearce, J.M. Energy Payback Time of a Solar Photovoltaic Powered Waste Plastic Recyclebot System. Recycling 2017, 2, 10. [CrossRef]

19. La Mantia, F.P.; Mistretta, M.C.; Palermo, S.; Koci, E.; Ceraulo, M. Thermomechanical degradation of PLA-based nanobiocomposite. Polym. Adv. Technol. 2015, 27, 308-313. [CrossRef]

20. Wu, D.; Hakkarainen, M. Recycling PLA to multifunctional oligomeric compatibilizers for PLA/starch composites. Eur. Polym. J. 2015, 64, 126-137. [CrossRef]

21. Srisawat, N.; Nithitanakul, M.; Srikulkit, K. Characterizations of Fibers Produced from Polypropylene/Silica Composite. J. Met. Mater. Miner. 2009, 19, 53-58.

22. Roy, S.B.; Ramaraj, B.; Shit, S.; Nayak, S.K. Polypropylene and potato starch biocomposites: Physicomechanical and thermal properties. J. Appl. Polym. Sci. 2011, 120, 3078-3086. [CrossRef]

23. Jafari, S.H.; Asadinezhad, A.; Vahid, A.K.; Khonakdar, H.A.; Wagenknecht, U.; Heinrich, G. Polypropylene/Poly(Trimethylene Terephthalate) Blend Nanocomposite: A Thermal Properties Study. Polym. Plast. Technol. Eng. 2012, 51, 682-688. [CrossRef]

24. Gao, M.; Yang, J.; Zhao, H.; He, H.; Hu, M.; Xie, S. Preparation Methods of Polypropylene/Nano-Silica/Styrene-EthyleneButylene-Styrene Composite and Its Effect on Electrical Properties. Polymers 2019, 11, 797. [CrossRef] [PubMed]

25. Guirguis, O.W.; Moselhey, M.T.H. Thermal and Structural Studies of Poly (Vinyl Alcohol) and Hydroxypropyl Cellulose Blends. Nat. Science. 2012, 4, 57-67. [CrossRef]

26. Peng, Z.; Kong, L.X.; Li, S.-D.; Spiridonov, P. Poly(vinyl alcohol)/Silica Nanocomposites: Morphology and Thermal Degradation Kinetics. J. Nanosci. Nanotechnol. 2006, 6, 3934-3938. [CrossRef]

27. Nakane, K.; Yamashita, T.; Iwakura, K.; Suzuki, F. Properties and Structure of Poly(Vinyl Alcohol)/Silica Composites. J. Appl. Polym. Sci. 1999, 74, 133-138. [CrossRef]

28. Mathew, L.; Narayanankutty, S.K. Cure Characteristics and Mechanical Properties of HRH Bonded Nylon-6 Short Fiber-NanosilicaAcrylonitrile Butadiene Rubber Hybrid Composite. Polym. Technol. Eng. 2008, 48, 75-81. [CrossRef]

29. Wangworn, P.; Wanakamol, P. Mechanical Properties of Compression-Molded Electrospun Silica Fiber/Nylon-6 Composites. Polym. Compos. 2019, 40, 1123-1131. [CrossRef]

30. Gianelli, W.; Ferrara, G.; Camino, G.; Pellegatti, G.; Rosenthal, J.; Trombini, R.C. Effect of Matrix Features on Polypropylene Layered Silicate Nanocomposites. Polymer 2005, 46, 7037-7046. [CrossRef]

31. Raquez, J.-M.; Habibi, Y.; Murariu, M.; Dubois, P. Polylactide (PLA)-based nanocomposites. Prog. Polym. Sci. 2013, 38, 1504-1542. [CrossRef]

32. Cicala, G.; Giordano, D.; Tosto, C.; Filippone, G.; Recca, A.; Blanco, I. Polylactide (PLA) Filaments a Biobased Solution for Additive Manufacturing: Correlating Rheology and Thermomechanical Properties with Printing Quality. Materials 2018, $11,1191$. [CrossRef] [PubMed]

33. Prasong, W.; Muanchan, P.; Ishigami, A.; Thumsorn, S.; Kurose, T.; Ito, H. Properties of 3D Printable Poly(lactic acid)/Poly(butylene adipate-co-terephthalate) Blends and Nano Talc Composites. J. Nanomater. 2020, 2020, 1-16. [CrossRef]

34. Corrêa, A.C.; de Santi, C.R.; Manrich, S. Synthetic Paper from Plastic Waste: The Effect of CaCO3 on Physical, Surface Properties and Printability. Macromol. Symp. 2006, 245-246, 611-620. [CrossRef]

35. Attaran, S.A.; Hassan, A.; Wahit, M.U. Materials for food packaging applications based on bio-based polymer nanocomposites. J. Thermoplast. Compos. Mater. 2017, 30, 143-173. [CrossRef]

36. Krupa, I.; Cecen, V.; Boudenne, A.; Prokeš, J.; Novák, I. The Mechanical and Adhesive Properties of Electrically and Thermally Conductive Polymeric Composites Based on High Density Polyethylene Filled with Nickel Powder. Mater. Des. 2013, 51, 620-628. [CrossRef]

37. Blanco, I. The Use of Composite Materials in 3D Printing. J. Compos. Sci. 2020, 4, 42. [CrossRef]

38. Lee, D.W.; Yoo, B.R. Advanced silica/polymer composites: Materials and applications. J. Ind. Eng. Chem. 2016, 38, 1-12. [CrossRef]

39. Ahmed, W.; Al-Douri, Y. Chapter 17 -Three-Dimensional Printing of Ceramic Powder Technology. In Metal Oxide Powder Technologies: Fundamentals, Processing Methods and Applications; Al-Douri, Y., Ed.; Metal Oxide Powder Technologies; Elsevier: Amsterdam, The Netherlands, 2020; pp. 351-383.

40. Hakim, R.H.; Cailloux, J.; Santana, O.O.; Bou, J.; Sánchez-Soto, M.; Odent, J.; Raquez, J.M.; Dubois, P.; Carrasco, F.; Maspoch, M.L. PLA/SiO2 Composites: Influence of the Filler Modifications on the Morphology, Crystallization Behavior, and Mechanical Properties. J. Appl. Polym. Sci. 2017, 134, 45367. [CrossRef]

41. Chhetri, S.; Adak, N.C.; Samanta, P.; Murmu, N.C.; Kuila, T. Functionalized Reduced Graphene Oxide/Epoxy Composites with Enhanced Mechanical Properties and Thermal Stability. Polym. Test. 2017, 63, 1-11. [CrossRef]

42. Mallakpour, S.; Naghdi, M. Polymer $/ \mathrm{SiO}_{2}$ nanocomposites: Production and applications. Prog. Mater. Sci. 2018, 97, 409-447. [CrossRef]

43. Lee, J.; Jin Lee, K.; Jang, J. Effect of Silica Nanofillers on Isothermal Crystallization of Poly(Vinyl Alcohol): In-Situ ATR-FTIR Study. Polym. Test. 2008, 27, 360-367. [CrossRef]

44. Tsai, P.-A.; Chiu, W.-M.; Lin, C.-E.; Wu, J.-H. Fabrication and Characterization of PLA/SiO $2 / \mathrm{Al}_{2} \mathrm{O}_{3}$ Composites Prepared by Sol-Gel Process. Polym. Technol. Eng. 2013, 52, 1488-1495. [CrossRef]

45. Santos, F.A.d.; Tavares, M.I.B. Development and Characterization of Hybrid Materials Based on Biodegradable PLA Matrix, Microcrystalline Cellulose and Organophilic Silica. Polimeros 2014, 24, 561-566. [CrossRef] 
46. Sörme, L.; Voxberg, E.; Rosenlund, J.; Jensen, S.; Augustsson, A. Coloured Plastic Bags for Kerbside Collection of Waste from Households-To Improve Waste Recycling. Recycling. 2019, 4, 20. [CrossRef]

47. Yang, C.; Tian, X.; Liu, T.; Cao, Y.; Li, D. 3D printing for continuous fiber reinforced thermoplastic composites: Mechanism and performance. Rapid Prototyp. J. 2017, 23, 209-215. [CrossRef]

48. Zuniga, J.M.; Peck, J.; Srivastava, R.; Katsavelis, D.; Carson, A. An Open Source 3D-Printed Transitional Hand Prosthesis for Children. JPO J. Prosthet. Orthot. 2016, 28, 103-108. [CrossRef]

49. Sodeifian, G.; Ghaseminejad, S.; Yousefi, A.A. Preparation of polypropylene/short glass fiber composite as Fused Deposition Modeling (FDM) filament. Results Phys. 2019, 12, 205-222. [CrossRef]

50. Fielding, G.A.; Bandyopadhyay, A.; Bose, S. Effects of Silica and Zinc Oxide Doping on Mechanical and Biological Properties of 3D Printed Tricalcium Phosphate Tissue Engineering Scaffolds. Dent. Mater. 2012, 28, 113-122. [CrossRef] [PubMed]

51. Abolghasemzade, S.; Pourmadadi, M.; Rashedi, H.; Yazdian, F.; Kianbakht, S.; Navaei-Nigjeh, M. PVA based nanofiber containing CQDs modified with silica NPs and silk fibroin accelerates wound healing in a rat model. J. Mater. Chem. B 2020, 9, 658-676. [CrossRef] [PubMed]

52. Kumar, A.; Patham, B.; Mohanty, S.; Nayak, S.K. Polypropylene-nano-silica nanocomposite foams: Mechanisms underlying foamability, and foam microstructure, crystallinity and mechanical properties. Polym. Int. 2019, 69, 373-386. [CrossRef]

53. Awad, S.A.; Khalaf, E.M. Investigation of improvement of properties of polypropylene modified by nano silica composites. Compos. Commun. 2019, 12, 59-63. [CrossRef]

54. Chi, X.; Cheng, L.; Liu, W.; Zhang, X.; Li, S. Characterization of Polypropylene Modified by Blending Elastomer and Nano-Silica. Materials 2018, 11, 1321. [CrossRef] [PubMed]

55. Zu, L.; Li, R.; Jin, L.; Lian, H.; Liu, Y.; Cui, X. Preparation and characterization of polypropylene/silica composite particle with interpenetrating network via hot emulsion sol-gel approach. Prog. Nat. Sci. 2014, 24, 42-49. [CrossRef]

56. Chung, H.; Das, S. Functionally Graded Nylon-11/Silica Nanocomposites Produced by Selective Laser Sintering. Mater. Sci. Eng. A. 2008, 487, 251-257. [CrossRef]

57. Chunze, Y.; Yusheng, S.; Jinsong, Y.; Jinhui, L. A Nanosilica/Nylon-12 Composite Powder for Selective Laser Sintering. J. Reinf. Plast. Compos. 2008, 28, 2889-2902. [CrossRef]

58. Ahmed, W.; Siraj, S.; Al-Marzouqi, A. Embracing Additive Manufacturing Technology through Fused Filament Fabrication for Antimicrobial with Enhanced Formulated Materials. Polymer 2021, 13, 1523. [CrossRef] [PubMed]

59. Alhamad, I.M.; Ahmed, W.K.; Ali, H.Z.; AlJassmi, H. 3D Printing Applications in Mechanical Engineering Education. 2019. Available online: https://brill.com/view/book/edcoll/9789004415133/BP000013.xml (accessed on 14 January 2021).

60. Ahmed, W.; Siraj, S.; Alnajjar, F.; Al Marzouqi, A.H.; Sharma, N.R. Applications of 3D Printing in Biomedical Engineering. In 3D Printed Implants for Joint Replacement; Springer: Singapore, 2021; pp. 97-119. [CrossRef]

61. Ahmed, W.; Ahmed, S.; Alnajjar, F.; Zaneldin, E. Mechanical Performance of Three-Dimensional Printed Sandwich Composite with a High-Flexible Core. Available online: https://journals.sagepub.com/doi/abs/10.1177/14644207211011729 (accessed on 14 January 2021).

62. Sgreccia, E.; Narducci, R.; Knauth, P.; Di Vona, M.L. Silica Containing Composite Anion Exchange Membranes by Sol-Gel Synthesis: A Short Review. Polymers 2021, 13, 1874. [CrossRef]

63. Bhat, K.A.; Prabhu, N.V.; Sangeetha, D. Polymer/silica composites fabricated by sol-gel technique for medical applications. Trends Biomater. Artif. Organs. 2012, 26.

64. Meer, S.; Kausar, A.; Iqbal, T. Attributes of Polymer and Silica Nanoparticle Composites: A Review. Polym. Plast. Techno. Eng. 2016, 55, 826-861. [CrossRef]

65. Ahmed, W.; Alabdouli, H.; Alqaydi, H.; Mansour, A.; Khawaja, H.A. Open Source 3D Printer: A Case Study. In Proceedings of the International Conference on Industrial Engineering and Operations Management, Dubai, United Arab Emirates, 10-12 March 2020; p. 10.

66. Hoffman, J.M. New Life for Shredded Plastic Waste. Mach. Design 2008, 80, 55-58.

67. Ahmed, W.; Siraj, S.; Al-Marzouqi, A. 3D Printing PLA Waste to Produce Ceramic Based Particulate Reinforced Composite Using Abundant Silica-Sand: Mechanical Properties Characterization. Polymers 2020, 12, 2579. [CrossRef] [PubMed]

68. Akyürek, F.; Yaman, K.; Tekiner, Z. An Experimental Work on Tool Wear Affected by Die Clearance and Punch Hardness. Arab. J. Sci. Eng. 2017, 42, 4683-4692. [CrossRef]

69. Suzuki, Y.; Yang, M.; Murakawa, M. Optimum Clearance in the Microblanking of Thin Foil of Austenitic Stainless Steel JIS SUS304 Studied from Shear Cut Surface and Punch Load. Materials 2020, 13, 678. [CrossRef] [PubMed]

70. Mucha, J. An experimental analysis of effects of various material tool's wear on burr during generator sheets blanking. Int. J. Adv. Manuf. Technol. 2010, 50, 495-507. [CrossRef]

71. D20. Committee, Guide for Determination of Thickness of Plastic Film Test Specimens; ASTM International: West Conshohocken, PA, USA, 2013.

72. Zdiri, K.; Elamri, A.; Hamdaoui, M.; Harzallah, O.; Khenoussi, N.; Brendlé, J. Reinforcement of recycled PP polymers by nanoparticles incorporation. Green Chem. Lett. Rev. 2018, 11, 296-311. [CrossRef]

73. Srebrenkoska, V.; Gaceva, G.B.; Avella, M.; Ericco, M.E.; Gentile, G. Utilization of Recycled Polypropylene for Production of Eco-Composites. Polym. Technol. Eng. 2009, 48, 1113-1120. [CrossRef]

74. Salman, S.A.; Bakr, N.A.; Homad, H.T. A Study of FTIR and some Mechanical Properties of Sodium Iodide (NaI) Salt Filled Polymer Polyvinyl Alcohol (PVA) Films. Int. Lett. Chem. Phys. Astron. 2018, 78, 30-38. [CrossRef] 
75. Meng, Q.; Hetzer, M.; De Kee, D. PLA/clay/wood nanocomposites: Nanoclay effects on mechanical and thermal properties. J. Compos. Mater. 2010, 45, 1145-1158. [CrossRef]

76. Watanabe, R.; Sugahara, A.; Hagihara, H.; Sato, H.; Mizukado, J.; Shinzawa, H. Study of matrix-filler interaction of polypropylene/silica composite by combined infrared (IR) spectroscopic imaging and disrelation mapping. Compos. Part A Appl. Sci. Manuf. 2020, 128, 105658. [CrossRef]

77. Li, Z.; Muiruri, J.K.; Thitsartarn, W.; Zhang, X.; Tan, B.H.; He, C. Biodegradable Silica Rubber Core-Shell Nanoparticles and Their Stereocomplex for Efficient PLA Toughening. Compos. Sci. Technol. 2018, 159, 11-17. [CrossRef]

78. Xia, S.; Liu, X.; Wang, J.; Kan, Z.; Chen, H.; Fu, W.; Li, Z. Role of Poly(Ethylene Glycol) Grafted Silica Nanoparticle Shape in Toughened PLA-Matrix Nanocomposites. Compos. Part B Eng. 2019, 168, 398-405. [CrossRef]

79. Wen, X.; Lin, Y.; Han, C.; Zhang, K.; Ran, X.; Li, Y.; Dong, L. Thermomechanical and optical properties of biodegradable poly(L-lactide)/silica nanocomposites by melt compounding. J. Appl. Polym. Sci. 2009, 114, 3379-3388. [CrossRef]

80. Liu, L.; Ma, H.; Zhu, X.; Fan, Y.; Jin, Z. Preparation and Properties of Polylactide/Nano-silica in Situ Composites. Pigment Resin Technol. 2010, 39, 27-31. [CrossRef]

81. Hao, X.; Kaschta, J.; Schubert, D.W. Viscous and Elastic Properties of Polylactide Melts Filled with Silica Particles: Effect of Particle Size and Concentration. Compos. Part B Eng. 2016, 89, 44-53. [CrossRef]

82. Siengchin, S. Impact, thermal and mechanical properties of high density polyethylene/flax/SiO2 composites: Effect of flax reinforcing structures. J. Reinf. Plast. Compos. 2012, 31, 959-966. [CrossRef]

83. Ultimaker PLA Material Data Sheet: Highly Versatile, Easy to Print. Available online: https://ultimaker.com/materials/pla (accessed on 7 August 2020).

84. Restrepo, I.; Medina, C.; Meruane, V.; Akbari-Fakhrabadi, A.; Flores, P.; Rodríguez-Llamazares, S. The effect of molecular weight and hydrolysis degree of poly(vinyl alcohol)(PVA) on the thermal and mechanical properties of poly(lactic acid)/PVA blends. Polimeros 2018, 28, 169-177. [CrossRef]

85. Krzysztof Pielichowski Tomasz Majka, Polymer Composites with Functionalized Nanoparticles; Elsevier: Amsterdam, The Netherlands, 2019.

86. Rybnikář, F.; Geil, P.H. Interactions at the PA-6/PA-66 Interface. J. Appl. Polym. Sci. 1992, 46, 797-803. [CrossRef]

87. Wei, Q.; Wang, Y.; Rao, Y.; Jiang, A.; Zhang, K.; Lu, T.; Chen, X. Evaluating the Effects of Nanosilica on Mechanical and Tribological Properties of Polyvinyl Alcohol/Polyacrylamide Polymer Composites for Artificial Cartilage from an Atomic Level. Polymer 2019, 11, 76. [CrossRef]

88. Jeevananda, T.; Kim, N.H.; Lee, J.H.; Basavarajaiah, S.; Urs, M.D.; Ranganathaiah, C. Investigation of Multi-Walled Carbon Nanotube-Reinforced High-Density Polyethylene/Carbon Black Nanocomposites Using Electrical, DSC and Positron Lifetime Spectroscopy Techniques. Polym. Int. 2009, 58, 775-780. [CrossRef]

89. Lei, Y.; Wu, Q.; Clemons, C.M.; Yao, F.; Xu, Y. Influence of nanoclay on properties of HDPE/wood composites. J. Appl. Polym. Sci. 2007, 106, 3958-3966. [CrossRef]

90. Jankong, S.; Srikulkit, K. Preparation of Polypropylene/Hydrophobic Silica Nanocomposite. Asia Pac. J. Sci. Technol. 2008, $13,621-626$.

91. D18 Committee. Test Methods for Laboratory Determination of Density (Unit Weight) of Soil Specimens; ASTM International: West Conshohocken, PA, USA, 2021.

92. Lee, I.K.; White, W.; Ingles, O.G. Soil Formation, Classification and Exploration. Princ. Geotech. Eng. 1983, 1-56.

93. D20 Committee. Test Methods for Density and Specific Gravity (Relative Density) of Plastics by Displacement; ASTM International: West Conshohocken, PA, USA, 2020.

94. Rothon, R. Particulate-Filled Polymer Composites; iSmithers Rapra Publishing: Shrewsbury, UK, 2003.

95. D20 Committee. Practice for Cutting Film and Sheeting Test Specimens; ASTM International: West Conshohocken, PA, USA, 2017; ASTM D6287-17.

96. Farah, S.; Anderson, D.G.; Langer, R. Physical and mechanical properties of PLA, and their functions in widespread applicationsA comprehensive review. Adv. Drug Deliv. Rev. 2016, 107, 367-392. [CrossRef] [PubMed]

97. Wypych, G. Handbook of Fillers-Book Reviews. IEEE Electr. Insul. Mag. 2004, 20, 64-65. [CrossRef]

98. Modjarrad, K.; Ebnesajjad, S.; McKeen, W.L. CH3-Plastics Used in Medical Devices. In Plastics Design Library, Handbook of Polymer Applications in Medicine and Medical Devices; Modjarrad, K., Ebnesajjad, S., Eds.; William Andrew Publishing: Norwich, NY, USA, 2014; pp. 21-53.

99. Ahmed, W.; Alnajjar, F.; Zaneldin, E.; Al-Marzouqi, A.H.; Gochoo, M.; Khalid, S. Implementing FDM 3D Printing Strategies Using Natural Fibers to Produce Biomass Composite. Materials 2020, 13, 4065. [CrossRef] [PubMed]

100. Novabeans-3D Priniter, 3D Scanner, 3D Pen, Filaments, 3D Services Provider. Available online: https://www.novabeans.com/ ultimakerfilaments / index.html (accessed on 17 January 2021).

101. Mikula, K.; Skrzypczak, D.; Izydorczyk, G.; Warchoł, J.; Moustakas, K.; Chojnacka, K.; Witek-Krowiak, A. 3D printing filament as a second life of waste plastics-A review. Environ. Sci. Pollut. Res. 2021, 28, 12321-12333. [CrossRef] [PubMed]

102. Anderson, I. Mechanical properties of specimens 3D printed with virgin and recycled polylactic acid. 3D Print. Addit. Manuf. 2017, 4, 110-115. [CrossRef]

103. Zenkiewicz, M.; Richert, J.; Rytlewski, P.; Moraczewski, K.; Stepczyńska, M.; Karasiewicz, T. Characterisation of multi-extruded poly(lactic acid). Polym. Test. 2009, 28, 12-418. [CrossRef]

104. Lu, B.; Li, D.; Tian, X. Development Trends in Additive Manufacturing and 3D Printing. Engineering 2015, 1, 085-089. [CrossRef] 